\title{
Phosphorylation by Aurora B kinase regulates caspase-2 activity and function
}

\author{
Yoon Lim $\mathbb{B}^{1} \cdot$ Dylan De Bellis $\mathbb{D}^{1} \cdot$ Jarrod J. Sandow $\mathbb{B}^{2,3} \cdot$ Luisa Capalbo ${ }^{4}$ Pier Paolo D'Avino $\mathbb{B}^{4} \cdot$ \\ James M. Murphy $\mathbb{B}^{2,3} \cdot$ Andrew I. Webb $\mathbb{D}^{2,3} \cdot$ Loretta Dorstyn $^{1} \cdot$ Sharad Kumar $\mathbb{D}^{1}$
}

Received: 19 March 2020 / Revised: 3 August 2020 / Accepted: 5 August 2020 / Published online: 18 August 2020

(c) The Author(s) 2020. This article is published with open access

\begin{abstract}
Mitotic catastrophe (MC) is an important oncosuppressive mechanism that serves to eliminate cells that become polyploid or aneuploid due to aberrant mitosis. Previous studies have demonstrated that the activation and catalytic function of caspase- 2 are key steps in MC to trigger apoptosis and/or cell cycle arrest of mitotically defective cells. However, the molecular mechanisms that regulate caspase-2 activation and its function are unclear. Here, we identify six new phosphorylation sites in caspase-2 and show that a key mitotic kinase, Aurora B kinase (AURKB), phosphorylates caspase-2 at the highly conserved residue S384. We demonstrate that phosphorylation at S384 blocks caspase-2 catalytic activity and apoptosis function in response to mitotic insults, without affecting caspase-2 dimerisation. Moreover, molecular modelling suggests that phosphorylation at S384 may affect substrate binding by caspase-2. We propose that caspase-2 S384 phosphorylation by AURKB is a key mechanism that controls caspase-2 activation during mitosis.
\end{abstract}

\section{Introduction}

Mitosis is a highly dynamic process that is tightly regulated by a series of surveillance mechanisms that ensure the faithful segregation of chromosomes into the nascent daughter cells,

These authors contributed equally: Loretta Dorstyn, Sharad Kumar

Edited by G. Melino

Supplementary information The online version of this article (https:// doi.org/10.1038/s41418-020-00604-y) contains supplementary material, which is available to authorized users.

Yoon Lim

yoon.lim@unisa.edu.au

$\triangle$ Sharad Kumar

sharad.kumar@unisa.edu.au

1 Centre for Cancer Biology, University of South Australia and SA Pathology, GPO Box 2471, Adelaide, SA 5001, Australia

2 The Walter and Eliza Hall Institute of Medical Research, Parkville, VIC 3052, Australia

3 Department of Medical Biology, University of Melbourne, Parkville, VIC 3050, Australia

4 Department of Pathology, University of Cambridge, Tennis Court Road, Cambridge CB2 1QP, UK thereby maintaining genomic integrity. Errors in karyokinesis and/or cytokinesis during cell division generate cells carrying abnormal genomic content (i.e. aneuploidy or polyploidy) [1]. The chromosomal passenger complex (CPC) is a key factor in controlling the proper execution of both karyokinesis and cytokinesis, especially through the activity of its kinase subunit Aurora B kinase (AURKB), to prevent the formation of aneuploid and polyploid cells [2]. However, when mitotic errors cannot be corrected, they ultimately trigger mitotic catastrophe (MC), a key mechanism that prevents the proliferation and survival of mitotically aberrant cells through either regulated cell death, such as apoptosis, or cellular senescence $[1,3]$. Failure of the MC process leads to persistent genomic instability, a well-characterised hallmark of cancer [4]. Therefore, MC is a critical mechanism to prevent cells from becoming tumourigenic.

Caspase-2, the most evolutionarily conserved member of the mammalian caspase family, was discovered over 2 decades ago [5]. Previous studies using knockout (KO) mice have demonstrated that caspase- 2 deficiency promotes tumour development following replicative or oncogenic stress [6-10]. Recent studies have demonstrated that caspase- 2 activation and its catalytic activity are critical steps in MC signalling. Our previous studies demonstrated that caspase-2-deficient cells acquire extensive aneuploidy following replicative stress in culture [11], following 
prolonged mitotic arrest caused by inhibition of polo-like kinase 1 (Plk1) [12] and in the bone marrow of aged caspase-2 KO mice [13]. This was partly caused by decreased Bid cleavage, reduced cell death, and clonogenic survival of aberrant mitotic cells [12]. Importantly, cells from mice harboring catalytic-dead caspase-2 (Casp2 $\left.{ }^{C 320 S}\right)$ also showed increased aneuploidy following prolonged mitotic arrest [12], suggesting importance of the activation and enzymatic activity of caspase- 2 in apoptotic death of aneuploid cells. Other studies have demonstrated that caspase-2 activation following cytokinesis failure following AURKB inhibition triggers cleavage of MDM2, leading to p53 stabilisation and cell cycle arrest, as an alternative mechanism to prevent aneuploidy and polyploidy [14, 15]. Although this evidence shows that caspase- 2 activation and its activity are required to prevent survival and proliferation of cells with mitotic defects, the molecular mechanisms have not been well defined.

Previous studies indicate that activation of caspase- 2 can be modulated by phosphorylation in different experimental conditions [16-18]. Caspase-2 activation is inhibited by phosphorylation at $\mathrm{S} 157$ by casein kinase-2 in TNF-alpharelated apoptosis-inducing ligand (TRAIL)-mediated apoptosis in cultured cells [17], S308 (S340 in human) by Cdk1cyclin B1 during mitosis [16] and S135 (S164 in human) by calmodulin-dependent protein kinase II (CaMKII) in Xenopus oocytes under nutrient rich conditions [18]. S340 is localised in the linker region between the large (P19) and small (P14) subunits, suggesting that phosphorylation at these sites acts to prevent caspase- 2 processing and activation [16]. Recently, phosphorylation at T180 of caspase-2 by mitogen-activated protein kinase (MAPK) is involved in lipid metabolism [19]. However, it is not known whether phosphorylation at these sites regulates caspase- 2 activation and its activity in response to aberrant and/or failed mitosis.

In this study, we identified a number of previously unknown phosphorylation sites in caspase-2. Specifically, we demonstrate AURKB phosphorylates caspase- 2 at the highly conserved S384 residue within the small subunit. Furthermore, our data indicate an alternative MC regulatory mechanism through AURKB-mediated inhibitory phosphorylation of caspase-2 and suggest that inhibition of AURKB activity is required to trigger apoptosis or cell cycle arrest following failed mitosis.

\section{Results}

\section{Identification of phosphorylation sites in caspase-2}

In this study, we mainly utilised U2OS cells as these cells have been used in similar studies [12, 14], arrest effectively in mitosis [20, 21] and undergo cell death following mitotic exit upon treatment with mitotic drugs [22, 23]. Previous studies have shown that phosphorylation can inhibit caspase-2 activation or regulate its interaction with other molecules under different physiological conditions [16-19]. Therefore, we set out to define all potential caspase-2 phosphorylation sites in viable cells in culture. To identify phosphorylation sites in caspase-2, liquid chromatographytandem mass spectrometry (LC-MS/MS) experiments were conducted using trypsin-digested GFP immunoprecipitates from U2OS-CASP2 ${ }^{-/-}$cells transiently expressing GFPtagged catalytically inactive mouse caspase-2-C320G. (Fig. 1a and Supplementary Fig. S1). The annotated peptide sequence demonstrates all of the peptide fragments used for phosphorylation site identification. In total, we identified 11 phosphorylation sites in caspase-2 (Fig. 1b, c), including previously characterised residues S157, S164, T180 and S340 [16, 18, 19], and six novel sites S24, S80, T161, S220, S346 and S384. Phosphorylation at T158 in human caspase2 has also been reported in the PHOSIDA database, but its role is functionally undefined [24].

Next, multiple amino acid sequence alignment showed that S80, S157, T158, T180 and S220 are conserved in mammals, whereas S340 and S346 are also conserved in Xenopus caspase-2. Interestingly, S164 and S384 are most highly conserved, especially S384, which is remarkably well conserved among the different species including Drosophila apical caspase Dronc and C. elegans CED3 (Fig. 1d). It is important to note that Dronc and CED3 respectively are the only CARD containing caspases in flies and nematodes and are functionally analogous to both mammalian caspase- 2 and caspase- 9 [25, 26]. This finding suggests that caspase-2 S384 residue might be functionally important.

\section{Phosphorylation regulates caspase- 2 activation and function}

The first step in caspase-2 activation is homodimerisation via its CARD, followed by autoprocessing, and ectopic expression of caspase-2 triggers cell death [27-29]. To functionally characterise the newly identified phosphorylation sites in caspase-2, we generated phospho-mimetic (Ser/ Glu) and phospho-deficient (Ser/Ala or Thr/Val) mutants for each residue and then examined whether transient expression of these mutants affected the processing and activation of caspase-2, by assessing the cleavage of its substrates Bid and MDM2 [14, 15, 30]. As expected, WT caspase-2-GFP but not the C320G mutant cleaved MDM2, generating a p60 cleavage fragment $(60 \mathrm{kDa})$ (Fig. 2a). While most of the phosphorylation mutants could cleave MDM2 to some extent, MDM2 cleavage was completely abolished by expression of the S384E caspase- 2 mutant (Fig. 2a). Similarly, we found that all the phosphorylation 


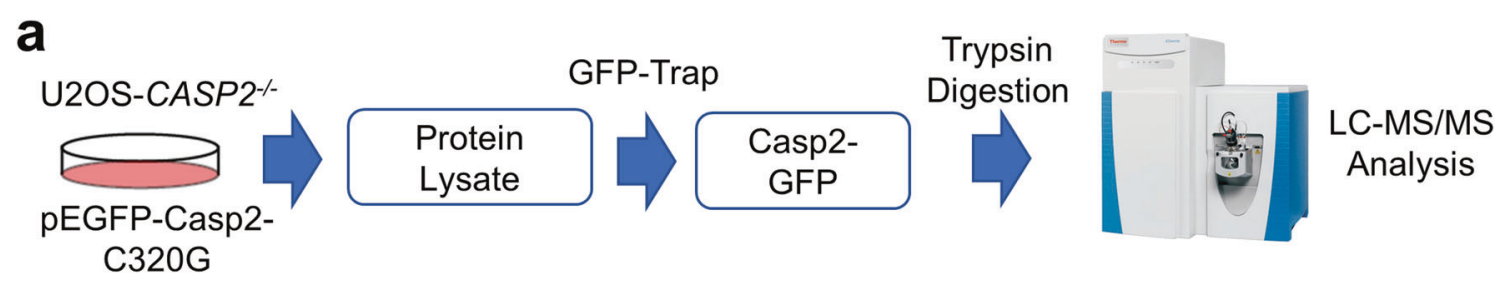

b

Caspase-2 phosphorylation sites identified by LC-MS/MS

\begin{tabular}{lcccccc}
\hline \multicolumn{1}{c}{ Peptide } & \multicolumn{2}{c}{$\begin{array}{c}\text { Position } \\
\text { in } \\
\text { peptide }\end{array}$} & $\begin{array}{c}\text { Charge } \\
\end{array}$ & $\begin{array}{c}\text { Mass } \\
\text { error } \\
{[\mathrm{ppm}]}\end{array}$ & $\begin{array}{c}\text { Peptide } \\
\text { location }\end{array}$ & $\begin{array}{c}\text { pS/T site } \\
\text { Localization } \\
\text { probability }\end{array}$ \\
\hline S(ph)RILAVCGMHPDHQETLK & 1 & 4 & -0.4984 & $24-41$ & 24 & 1.00 \\
GGS(ph)FSQNVELLNLLPK & 3 & 2 & -2.498 & $78-93$ & 80 & 0.99 \\
QLRLS(ph)TDATEHS(ph)LDNGDGPPCLLVK & 5 & 3 & -0.59 & $153-177$ & 157 & 0.98 \\
LST(ph)DAT(ph)EHSLDNGDGPPCLLVK & 3 & 2 & -2.3533 & $156-177$ & 158 & 0.71 \\
LS(ph)T(ph)DAT(ph)EHS(ph)LDNGDGPPCLLVK & 6 & 3 & -1.1089 & $153-177$ & 161 & 0.96 \\
LS(ph)T(ph)DAT(ph)EHS(ph)LDNGDGPPCLLVK & 9 & 2 & -1.7132 & $153-177$ & 164 & 1.00 \\
PCT(ph)PEFYQAHY(ph)QLAYR & 3 & 3 & -0.2975 & $178-193$ & 180 & 1.00 \\
S(ph)GGDVDHTTLVTLFK & 1 & 2 & -0.1515 & $220-234$ & 220 & 1.00 \\
NHT(ph)QS(ph)PGCEESDAGKEELMK & 5 & 3 & -1.2279 & $336-355$ & 340 & 0.98 \\
NHTQS(ph)PGCEES(ph)DAGKEELMK & 11 & 3 & -0.585 & $336-355$ & 346 & 0.98 \\
RGS(ph)WYIEALTQVFSER & 3 & 2 & 0.279 & $382-397$ & 384 & 1.00 \\
\hline
\end{tabular}

C

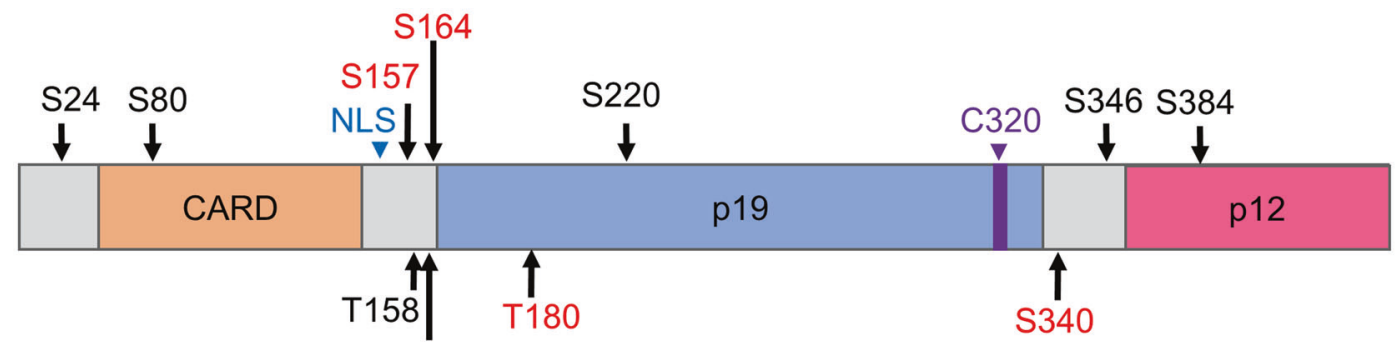

d

T161

\begin{tabular}{|c|c|c|c|c|c|}
\hline & 24 & 80 & 157 & 158161 & 164 \\
\hline Human & AADRGRRIL QAK & JGS- & KLRLS- & --TDTVE & SLDNKDGP---VCLQVKPCTPE \\
\hline Mouse & AADRRSRIL QAK & & QLRLS- & --TDATEF & SLDNGDGP---PCLLVKPCTPE \\
\hline Rat & AADRRSRIL QAK & & QSRLS- & - -TDTME & SLDNGDGP---PCLQVKPCTPE \\
\hline nopus & $-------\mid$ MAYI & $\mathrm{RSD}-----$ & GRQIC- & ----- REYREI & SIDDGDGP---VTVQL--CSVN \\
\hline ED3 & $\mathrm{NSC}$ & GTV- & NSSFTC & GCSSLGYSSSRN & SFSKASGP---TQYIFHEEDMN \\
\hline Dronc & --MQPPEL QDLI & JGKPFNMD & KLRNE- & $---\mathrm{P}---\mathrm{LGALTH}$ & YVGVVDGPEVKKSKKIHGGDSA \\
\hline & 220 & 340 & 346 & 38 & \\
\hline dman & EKELEFRSGGDVD & HAGSPGCE & ESDAG & TAAMRNTKRGS & WYIEAL \\
\hline ouse & EKDLEFRSGGDVD & HTQSPGCE & ESDAG & NAAMRNTKRGS & WYIEAL \\
\hline Rat & EKDLEFRSGGDVD & HAQSPGCE & ESDAG & NAAMRNTKRGS & WYIEAL \\
\hline Xenopus & TPDLDYRCGGEVD & QSGSPGCE & QSDAG & TVSLRNTKRGS & WFVQDL \\
\hline CED3 & --QMPTRNGTKAD & AFLRRGWD & DNRDGP & YVSWRNSARGS & WFIQAV \\
\hline Dronc & -DQNRRRIGAEKD & NLMEPVYT & AQEEK & YVTHRDLDTGS & WYIQKE \\
\hline
\end{tabular}

site mutants, except S384E, showed reduced levels or loss of full-length Bid, indicating complete cleavage. The C320G mutant did not induce cleavage of Bid as expected
(Fig. 2b). We also observed reduced autoprocessing of S384E, to a similar extent as seen with C320G. This was shown by higher levels of full-length caspase-2-GFP protein 
Fig. 1 Proteomic analysis identified six new phosphorylation sites in caspase-2. a Schematic diagram of phosphorylation site analysis of caspase-2. b Caspase-2 phosphorylation sites identified by LC-MS/MS. The phosphorylated amino acid position, charge, mass error, peptide location in caspase-2, phosphorylated $\mathrm{S} / \mathrm{T}$ site position in caspase-2 and localisation probability are indicated. Phosphorylated residues are indicated in brackets. Spectra for the peptides in (b) can be found in Supplementary Fig. S2. c Phosphorylation sites in caspase-2 identified by mass spectrometry. Functionally reported sites are indicated in red. S (Ser) or T (Thr) (in black) indicates positions of novel potential phosphorylation sites. NLS nuclear localisation signal. C320 catalytic Cys. d Multiple amino acid sequence alignment showing conservation of phosphorylation sites in caspase-2 from different species. Newly identified and known phosphorylation sites with high homology are shaded in purple and grey, respectively.
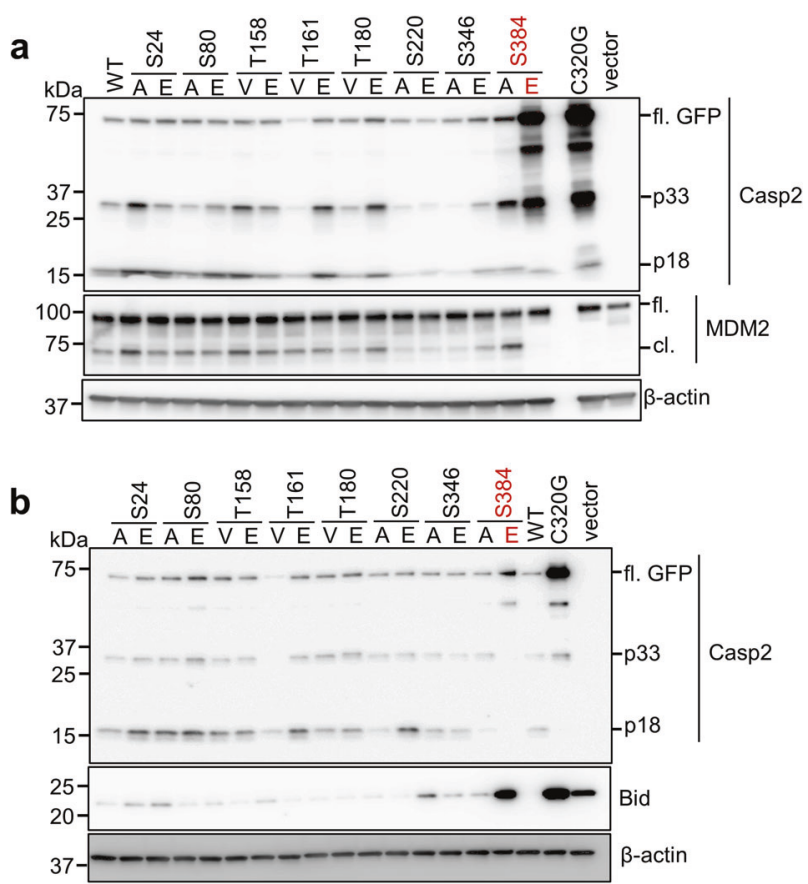

Fig. 2 Caspase-2-S384E mutant does not cleave MDM2 or Bid. a U2OS-CASP2 $2^{-1-}$ cells were transfected with $1 \mu \mathrm{g}$ of GFP mock vector, or GFP-tagged caspase-2 WT, C320G, or phosphorylation site mutants as indicated. Cell lysates were subjected to immunoblotting with the indicated antibodies. $\beta$-actin was used as loading control. b U2OS-CASP2 $2^{-1-}$ cells were co-transfected with $1 \mu \mathrm{g}$ of GFP mock vector, or GFP-tagged caspase-2 WT, C320G, or phosphorylation site mutants along with $500 \mathrm{ng}$ of Bid-HA. Cell lysates were subjected to immunoblotting with the indicated antibodies. $\beta$-actin was used as loading control.

(74 kDa) and reduced levels of the $18 \mathrm{kDa}$ subunit band compared to WT caspase- 2 or other phospho site mutants (Fig. 2a, b). These results demonstrate that the caspase-2 phospho-mimetic S384E mutation affects its autoprocessing and catalytic activity. Consistent with these findings, and similar to the C320G mutant, the expression of S384E also exhibited reduced ability to promote cell death compared to
WT or S384A in Casp2 ${ }^{-1-}$ immortalised mouse embryonic fibroblasts (MEFs) (Supplementary Fig. S3a, b).

We next assessed the enzymatic activity of the various caspase-2 phosphorylation mutant cell lysates using an in vitro caspase activity assay with the selective fluorogenic caspase-2 substrate, VDVAD-AFC [31, 32]. Several mutants showed significantly reduced VDVADase cleavage activity compared to WT caspase-2, including T180V, S220A, S220E, S346A, S384A and S384E (Supplementary Fig. S4a). Interestingly, only the S384E mutant showed a complete absence of enzymatic activity, similar to C320G or the vector control (Supplementary Fig. S4a), further demonstrating that mutation of this site impairs caspase-2 processing and substrate cleavage (Fig. 2). As the S384A mutation also showed reduced enzymatic activity in vitro, we generated additional unphosphorylatable mutants, including Ser-to-Gly (small amino acid) and Ser-to-Thr (uncharged, polar amino acid like serine) mutations at this site. We observed that, similar to S384A, both the S384G and S384T mutants were still able to cleave MDM2 and could also be processed in transfected cells (Supplementary Fig. S4b). Together, these results indicate that phosphorylation at S384 inhibits caspase-2 activation and activity in cells and that several phosphorylation site mutations can affect the enzymatic activity of caspase-2, but they do not impair its substrate cleavage and cell death inducing activity.

\section{Caspase-2-S384E does not disrupt dimerisation}

As homodimerisation is sufficient for initial caspase-2 activation [27], we examined whether the S384E mutation affected caspase-2 dimerisation using the bimolecular fluorescence complementation (BiFC) assay, a visualizing tool of protein-protein interaction [12,33], with full-length caspase-2-S384E and CASP2-C320A. We blocked mitosis using the Plk1 inhibitor BI2536 (BI), which we have previously demonstrated to result in caspase- 2 dimerisation [12]. There were no differences in dimerisation of caspase2-S384E or CASP2-C320A between control (DMSO) and BI treatment (Fig. 3a, b). Expression of GST recombinant caspase-2-WT, C320G or S384E in E. coli showed that WT GST-caspase-2 was cleaved to form an intermediate $(\sim 50$ $\mathrm{kDa})$ and fully processed large subunit $(18 \mathrm{kDa})$, whereas GST-caspase-2-S384E was not processed and behaved like the recombinant C320G protein (Fig. 3c). This demonstrates that caspase-2-S384E substitution prevents autoprocessing of caspase-2. Caspase assays using VDVAD-AMC showed robust catalytic activity by WT caspase- 2 but not by both the C320G and S384E (Fig. 3d), which further confirmed that caspase-2-S384E mutant protein lacks catalytic activity. Our data suggest that phosphorylation at S384 does not prevent the initial caspase-2 dimerisation event, but 
a
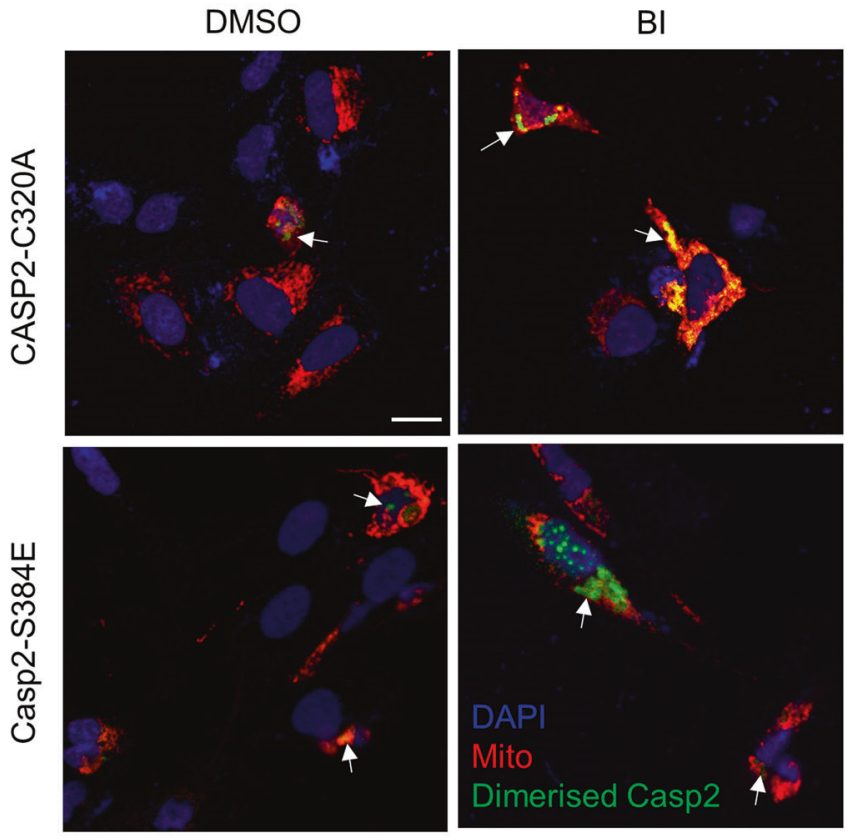

$\mathrm{BI}$

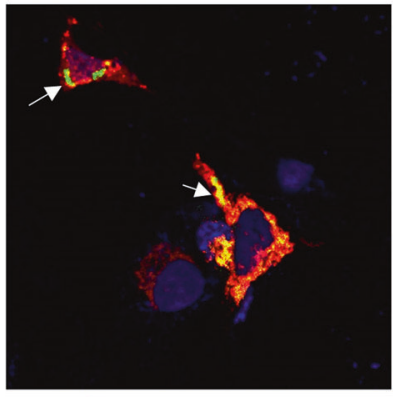

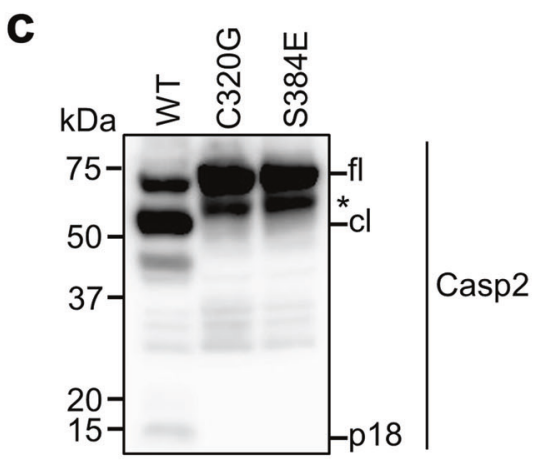

Fig. 3 Caspase-2-S384E mutant can still homodimerise but lacks enzymatic activity. a Representative confocal images showing dimerisation of Casp2-S384E or CASP2-C320A by BiFC. U2OS$C A S P 2^{-1-}$ cells were transfected with Casp2-S384E or CASP2-C320A $\mathrm{BiFC}$ constructs, respectively, together with pDsRED-Mito as transfection reporter and treated with DMSO or $100 \mathrm{nM} \mathrm{BI} 2536$ (BI) for 24 h. All cells were also treated with z-VAD $(20 \mu \mathrm{M})$, pan-caspase inhibitor. DAPI (blue); pDsRED-Mito (red). Arrows indicate dimerised caspase-2 (Green). Scale bar $=20 \mu \mathrm{m}$. b Quantitation of relative

inhibits autoproteolysis and downstream activation, and therefore likely exerts a dominant negative function.

\section{Caspase-2 S384 is a target of Aurora B kinase}

We used computational tools and databases including PHOSIDA, Scansite and KinasePhos 2.0 and identified AURKB as a potential kinase for phosphorylation of S384 in caspase-2. The consensus phosphorylation motifs for b

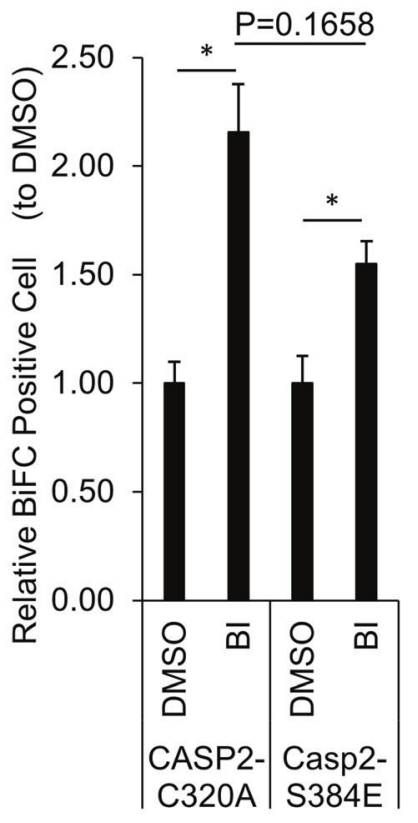

d

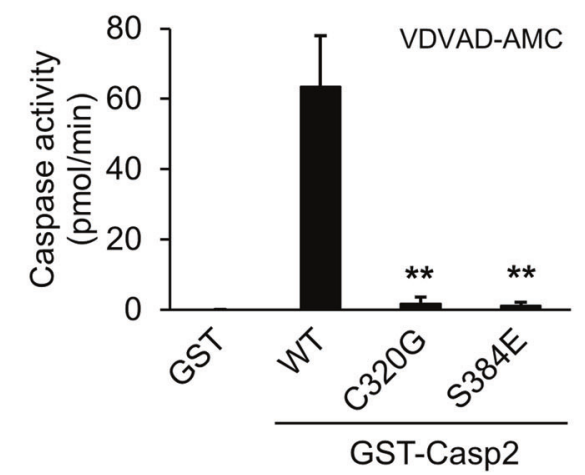

BiFC-positive cells are indicated. ${ }^{*} p<0.05$. c Immunoblot analysis of recombinant GST-caspase-2-WT, C320G and S384E protein expression and autoprocessing. '*', truncated GST-caspase-2. d Caspase activity of recombinant GST-caspase-2-WT, C320G and S384E protein, was assessed by cleavage of VDVAD-AMC. GST protein was used as a control. Data represented as mean \pm SEM from three independent experiments. ${ }^{* *} p<0.01$ compared to GST-caspase2-WT.

AURKB are (K/R)1-3-X-(S/T) or (K/R)-(R/K)-X0-2-(S/T), where $\mathrm{X}$ indicates any amino acid $[34,35]$. Such a sequence is present around S384 in caspase-2 (Fig. 1d). We first performed a GST-Casp2 pull-down assay to examine whether AURKB directly binds to caspase- 2 and found that GST-Casp2 full-length (GST-Casp2-fl) coprecipitated with AURKB (Fig. 4a). Furthermore, a small peptide fragment of caspase-2 comprising the S384 residue (aa 363-423; GSTCasp2 263-423) also coprecipitated with AURKB (Fig. 4b). 
a

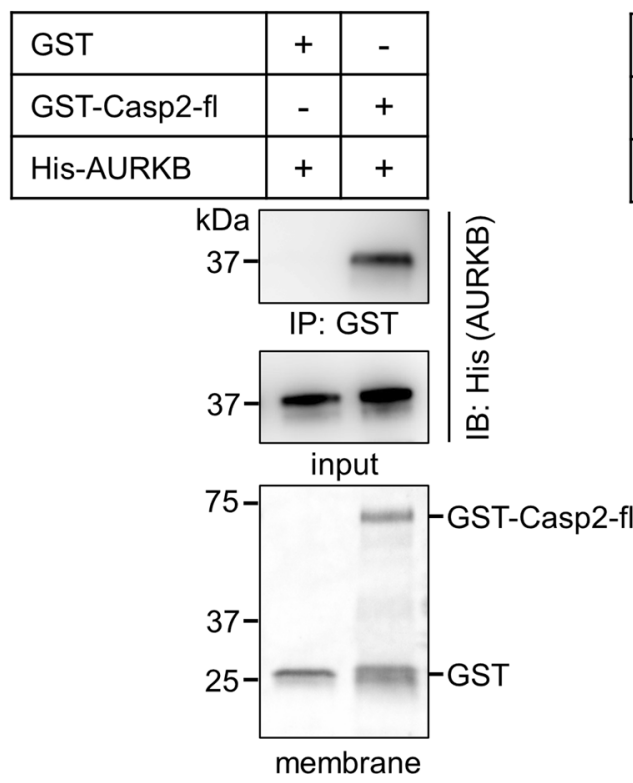

b
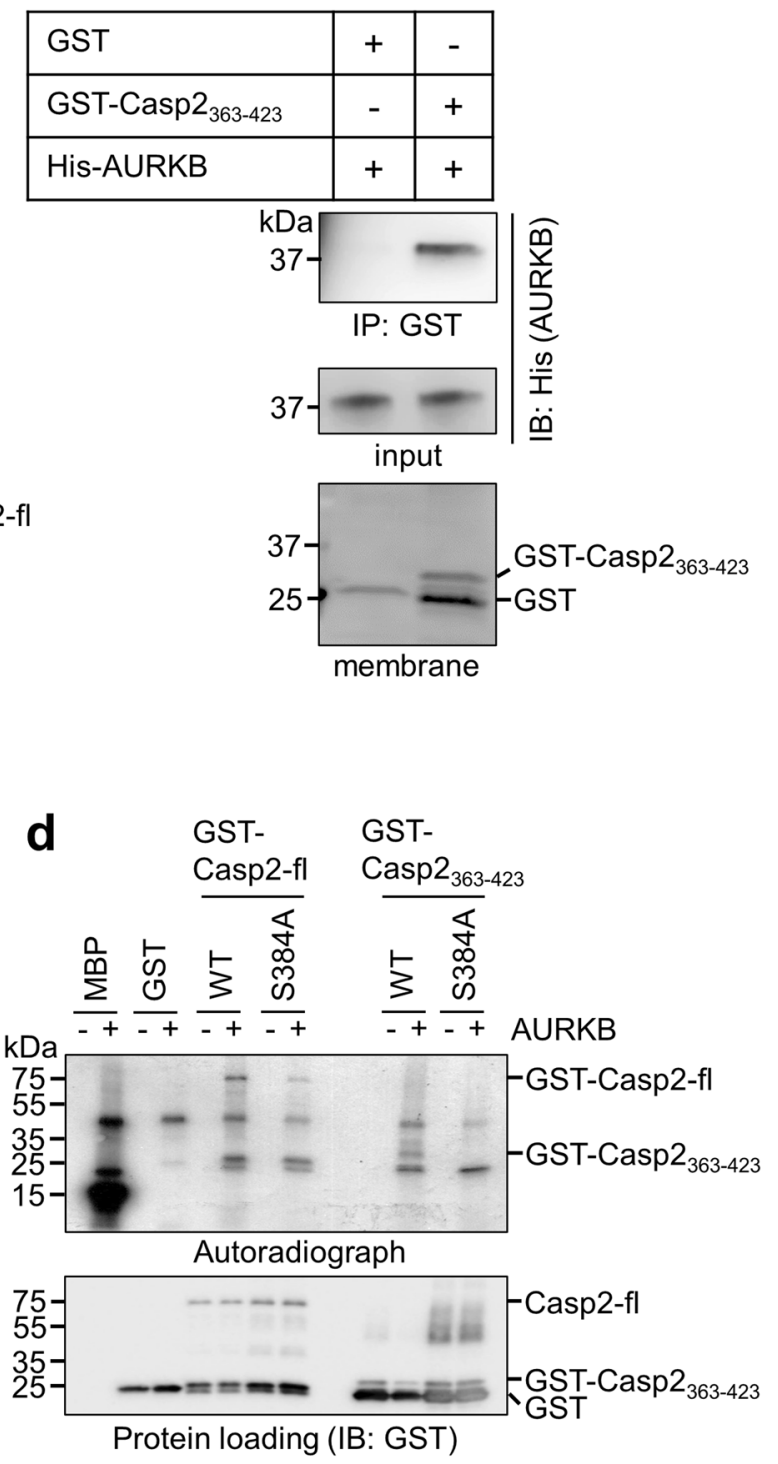

pHis-H3

Stain-free

membrane

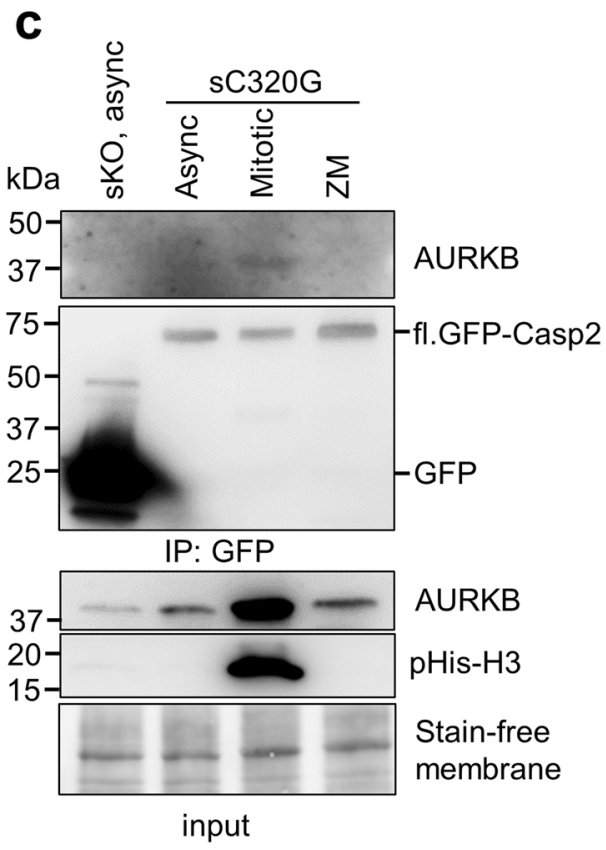

Fig. 4 Aurora B kinase phosphorylates caspase-2 at S384 in vitro. a, b In vitro interaction between purified recombinant GST-Casp2C320G (GST-Casp2-fl) or GST-Casp2 $363-423^{-W T}$ and His-AURKB was determined by GST pull-down assay. Stain-free membrane shows protein loading amount for GST or GST-Casp2. Antibodies used are indicated. c U2OS-CASP2 ${ }^{-1-}$ cells stably expressing GFP (sKO) or GFP-caspase-2-C320G (s320G) were used. GFP or GFP-caspase-2C320G were immunoprecipitated (IP) with GFP-Trap from the asynchronous (Async), mitotic or ZM447439 (ZM)-treated cells

To examine the interaction between caspase- 2 and AURKB in cells, we performed a coimmunoprecipitation (Co-IP) experiment using U2OS-CASP2 ${ }^{-/-}$cells stably expressing GFP (sKO) or GFP-caspase-2-C320G (sC320G). AURKB and subjected to immunoblotting with the indicated antibodies. Phospho-histone H3 (pHis-H3) was used as mitosis marker. Stain-free membrane was used as loading control. d GST-Casp2-fl WT, GSTCasp2-fl S384A, GST-Casp2 2363-423 WT, GST-Casp2 2363-423 S384A or GST was subjected to in vitro phosphorylation by incubation with AURKB and $\left[\gamma-{ }^{32} \mathrm{P}\right]-\mathrm{ATP}$ and analysed by autoradiography. IB with GST antibody shows equal loading. MBP, myeloid basic protein was used as positive control for AURKB phosphorylation.

coimmunoprecipitated with caspase-2 predominantly in the mitotic cell fraction but not in asynchronous or AURKB inhibitor (ZM) treated cells (Fig. 4c). Next, we performed an in vitro phosphorylation assay using AURKB with either 
GST-Casp2-fl WT or the S384A mutant The result demonstrated that full-length caspase- 2 is phosphorylated by AURKB (Fig. 4d). Furthermore, in vitro phosphorylation using GST-Casp2 $363-423$ WT or S384A confirmed that S384 of caspase- 2 is phosphorylated by AURKB (Fig. 4d). Notably, AURKB phosphorylation was almost completely abolished in the GST-Casp2 $263-423$ S384A fragment but was only diminished in the GST-Casp2-fl S384A (Fig. 4d), suggesting that AURKB might phosphorylate additional residues besides S384. Interestingly, Aurora A kinase (AURKA) did not phosphorylate S384 (Supplementary Fig. S5), indicating that this residue is a specific site for AURKB. Together, these data suggest that $\mathrm{S} 384$ of caspase-2 is target of AURKB and is predominantly phosphorylated in mitosis.

\section{Caspase-2-S384E expression results in increased polyploidy and resistance to cell death following mitotic stress}

To further characterize the functional consequence of phosphorylation at S384, we established a series of U2OS cells stably expressing GFP (sWT) or U2OS-CASP2 ${ }^{-1-}$ cells stably expressing GFP (sKO), GFP-tagged caspase-2C320G (sC320G) or S384E (sS384E clones \#1 and \#2) (Supplementary Fig. S6). These cell lines were treated with the AURKB inhibitor ZM447439 (ZM) [36] to induce polyploidy and then cleavage of caspase- 2 and its substrate MDM2, was analysed by immunoblotting (IB) and DNA content was measured by flow cytometry. Consistent with previous reports [14, 15], sWT cells showed cleavage of caspase-2 (p18 kDa), MDM2 and increased p53 and p21 accumulation in response to AURKB inhibition (Fig. 5a). The sKO cells still showed increased p53 levels following ZM treatment, albeit less than sWT cells, but p21 levels were not increased and cleavage of MDM2 was absent, which is consistent with previous findings (Fig. 5a) [14]. Interestingly, similar to sKO and sC320G, the two independent sS384E cell lines also showed absence of MDM2 cleavage and p21 increase in response to ZM, while still exhibiting induction of p53 (Fig. 5a). DNA content analysis of sKO cells showed significantly increased polyploid $(>4 N)$ cell accumulation compared to sWT cells (Fig. 5b, c), which is consistent with previous reports [14, 15]. Similarly, sC320G and sS384E cell lines also showed increased polyploidy following ZM treatment (Fig. 5b, c).

We also used an alternative approach to induce polyploidy by treating cells with blebbistatin to inhibit nonmuscle myosin II, which plays an essential role in the constriction of the actomyosin contractile ring during cytokinesis [37, 38]. Importantly, similar results were observed when the U2OS stable cell lines were treated with blebbistatin, although the accumulation of p53 reduced
(Fig. 6a), particularly when compared to treatment with the AURKB inhibitor, AZD1152 [36] (Supplementary Fig. S7a) in U2OS parental and $C A S P 2^{-/-}$cells. Polyploidy was also significantly increased in sKO, sC320G and sS384E cell lines compared to the sWT although the increase is not as robust as with AURKB inhibitor treatment (Fig. 6b and Supplementary Fig. S7b).

We also treated U2OS stable cell lines with the Plk1 inhibitor, BI2536 (BI), which induces mitotic arrest, chromosome missegregation, aneuploidy and caspase-2 dependent apoptotic cell death [12]. Following treatment with BI, the sKO, sC320G and sS384E cell lines were more resistant to apoptosis than sWT cells (Fig. 7a). The sWT cells also showed caspase- 2 activation, cleavage of PARP, caspase-3 and Bid, demonstrating BI-induced cell death (Fig. 7b). As previously reported, sKO and $\mathrm{sC} 320 \mathrm{G}$ cells showed reduced cleavage of PARP, Bid and caspase-3 [12] and this was also observed in the sS384E cell lines (Fig. 7b). Taken together, these experiments confirmed that phosphorylation of S384 inhibits caspase-2 activity and its cell death function.

We then examined whether re-expression of caspase-2 WT, S384A or S384E can rescue caspase-2-mediated MC signalling, in two different cell lines, U2OS-CASP2 ${ }^{-/-}$and A549-CASP2 $2^{-1-}$ cells. Only the caspase-2 WT and S384A expressing cells showed caspase-2 activation and complete processing (p18) following ZM treatment, whereas C320G and S384E did not (Supplementary Fig. S8a, b). Also, MDM2 cleavage was observed in caspase-2 WT or S384A expressing U2OS-CASP2 $2^{-/-}$and A549-CASP2 $2^{-/-}$cells, but not in cells expressing C320G or S384E (Supplementary Fig. S8a, b). Interestingly, more MDM2 cleavage was observed in S384A expressing cells compared to the cells expressing WT caspase-2. These data further indicate that phosphorylation at S384 in caspase-2 is critical to regulate caspase- 2 activation and activity in $\mathrm{MC}$.

\section{Discussion}

In the present study, we identified six new phosphorylation sites in mouse caspase- 2 by LC-MS/MS. We used the catalytically inactive caspase-2-C320G mutant, because unlike WT caspase-2, it is not associated with cytotoxicity when expressed ectopically [27]. This allowed us to identify new phosphorylation sites associated with full-length caspase-2 zymogen. Of the six newly identified phosphorylation sites, we found that S384, which is highly conserved, is critical for the regulation of caspase-2 activity and function. Our studies utilising re-expression of caspase- 2 mutants in caspase-2 deficient cells demonstrated that the caspase-2S384E phospho-mimetic mutant prevents caspase- 2 activation and its catalytic activity. Firstly, S384E caspase-2 


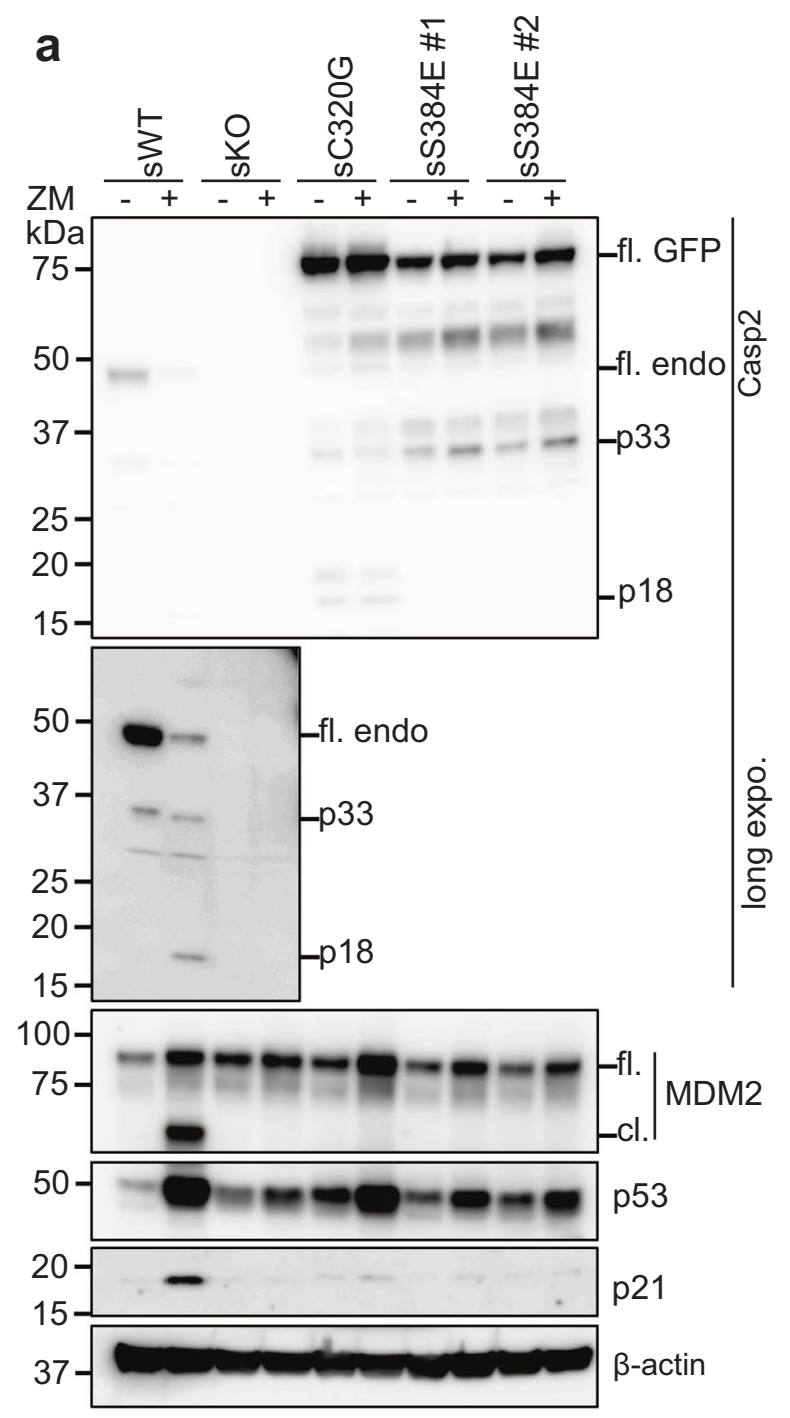

b

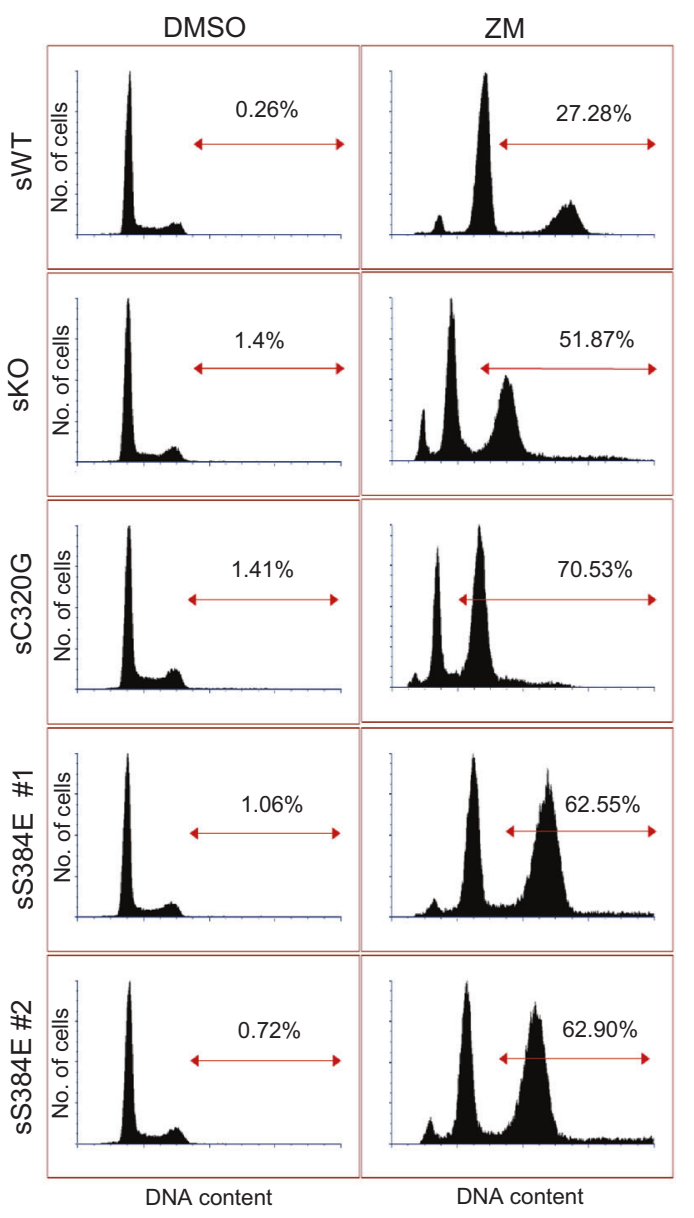

C

ZM, 48h

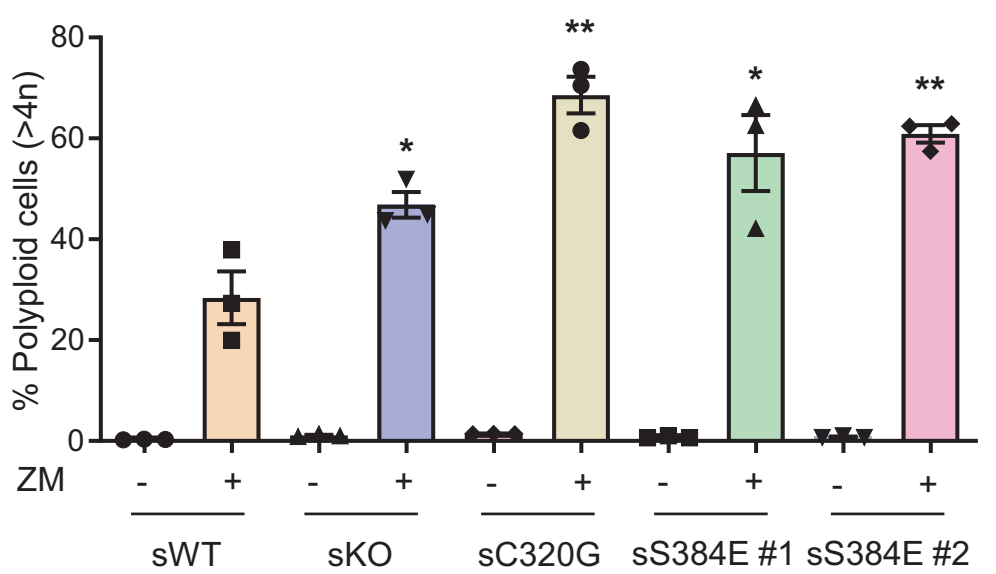

shows reduced autoprocessing of recombinant protein in cells. While we observed some caspase- 2 cleaved products (p33 and p18) in S384E and C320G overexpressing cells, recombinant protein did not show caspase-2 autoprocessing or catalytic activity. These cleaved products were reduced or absent when the $\mathrm{C} 320 \mathrm{G}$ or S384E mutants were 
Fig. 5 Caspase-2-S384E expressing cells fail to cleave MDM2 and show increased polyploidy following AURKB inhibition. GFPexpressing U2OS (sWT) and U2OS-CASP2 $2^{-1-}$ expressing GFP (sKO), GFP-caspase-2-C320G (sC320G) or GFP-caspase-2-S384E (sS384 \#1 and \#2) were treated with DMSO or $2 \mu \mathrm{M}$ ZM447439 (ZM) for $48 \mathrm{~h}$ and subjected to immunoblot and DNA content analysis. a Representative immunoblots (from three independent experiments) of cell lysates from treated stable cell lines. Antibodies used for immunoblotting are as indicated. $\beta$-actin was used as loading control. b Representative flow cytometric profiles of the DNA content in cells following ZM treatment. The percentage represents polyploid cells $(>4 N)$, which was calculated using FACS Express 6 cell cycle analysis module. c Graph comparing percentage of cells with polyploid $(>4 N)$ DNA content following ZM treatment. Mean \pm SEM; $n=3$. $* p<0.05$; $* * p<0.01$ compared to $\mathrm{sWT}+\mathrm{ZM}$.

transiently expressed in U2OS-CASP2 $2^{-/} / C A S P 3^{-/-}$cells (Supplementary Fig, S9) indicating the cleavage is likely caused by caspase-3 [39] or other cellular proteases. Secondly, S384E was unable to cleave the known caspase-2 substrates, MDM2 and Bid. Thirdly, caspase-2-S384E can still homodimerise but is catalytically inactive. Lastly, expression of the caspase-2-S384E shows predominantly nuclear localisation, similar to the C320G mutant, which may also impede activation by other caspases in the cytosol. Overall our results suggest that while S384E does not affect dimerisation, the first step of caspase-2 activation, it prevents autoproteolytic processing, cytosolic localisation and complete caspase- 2 activation. This may be in part caused by steric hindrance on the substrate binding site. These data suggest that S384E caspase-2 likely acts as a dominant negative protein.

Caspase- 2 is the only member of the caspase family that preferentially recognises a pentapeptide, such as VDVAD or ADVAD, as substrates over a tetrapeptide sequence $[31,32,40]$. T380 and Y420 are key residues that have been shown to be critical for binding the P5 residue [41]. These residues form hydrogen bonds with P5 Val in VDVAD or Ala in ADVAD pentapeptide substrates [41]. Also, W385 forms a hydrogen bond with P4 Asp. Interestingly, S384 localises next to W385 and close to T380 although it may not directly interact with the substrate [41]. This suggests that phosphorylation at S384 may cause an interference with substrate binding (Fig. 8a, b) preventing the catalytic activity of caspase- 2 .

We examined four different substitution mutants of S384 and found that only the S384E phospho-mimetic mutant was enzymatically inactive. Although various other amino acid substitutions on S384 may affect cleavage ability of caspase-2, we have shown here that the region directly surrounding S384 of caspase- 2 can bind to AURKB in vitro and in vivo (Fig. $4 \mathrm{a}-\mathrm{C}$ ), and $\mathrm{S} 384$ is phosphorylated by AURKB (Fig. 4d). In addition, expression of the phosphodeficient S384A mutant in caspase-2 deficient cells, can rescue the cleavage of MDM2 following aberrant mitosis.
However, phosphorylation of S384 is unable to rescue MC signalling (as demonstrated by expression of S384E) (Supplementary Fig. S8). These findings, demonstrate that phosphorylation of S384 by AURKB is critical to prevent caspase- 2 activation and activity.

Multiple kinases are responsible for phosphorylation of caspases [42]. Our study identified AURKB as an important additional kinase that phosphorylates caspase-2 at S384. We also examined other kinases (including CaMKII, PKA, PAK1, Cdk1, Plk1 and MAPK) but none of them phosphorylated the S384 site in caspase-2 (data not shown). Analysis with the GPS 5.0 software (http://gps.biocuckoo. cn) predicted five possible additional AURKB phosphorylation sites in caspase-2, of which only two, S24 and S157, were identified by MS in this study. We tested S24 phospho-mutants but found this residue was not essential for caspase-2 function. While S157 may be an AURKB target site, our data indicate that phosphorylation on S384 is sufficient to prevent activation and catalytic activity of caspase-2. AURKB has various critical functions in mitosis, including chromatin condensation, kinetochore-microtubule error correction and cytokinesis [43]. Therefore, our findings suggest that AURKB phosphorylation maintains caspase-2 in an inactive state throughout cell division. Notably, caspase-2 is also regulated by Cdk1-mediated inhibitory phosphorylation at S340 during mitosis [16]. However, while Cdk1 activity is inhibited following degradation of its cyclin B partner at anaphase onset, AURKB remains active until late cytokinesis [44]. Importantly, AURKB, along with its CPC partners, can delay the final separation (i.e. abscission) of the two daughter cells in the presence of lagging chromatin at the cleavage site to prevent aneuploidy and polyploidy [45]. Therefore, it appears that caspase- 2 is under tight regulation by multiple mitotic kinases to prevent any accidental cell death during cell division. Our studies using the S384E mutant expression in U2OS cells and recombinant S384E caspase-2 protein in vitro demonstrate that phosphorylation at S384 prevents caspase- 2 catalytic activity and function. Therefore, the inhibition of S384 phosphorylation by specific targeting of this site, or by targeting AURKB may be an effective mechanism of activating caspase-2 in cycling cells. However, it would be important to decipher whether S384 dephosphorylation could effectively activate caspase2 during other cell cycle stages or in senescent cells. Interestingly, blebbistatin, which does not inhibit AURKB, also causes cytokinesis failure and caspase- 2 activation indicating potentially differential regulation of caspase- 2 at different mitotic stages. Importantly, the caspase-2-S384E was also not activated following blebbistatin treatment, suggesting an important role for AURKB-mediated phosphorylation in regulating caspase- 2 activation during general cytokinesis failure. It has been shown that PP1 can 
a

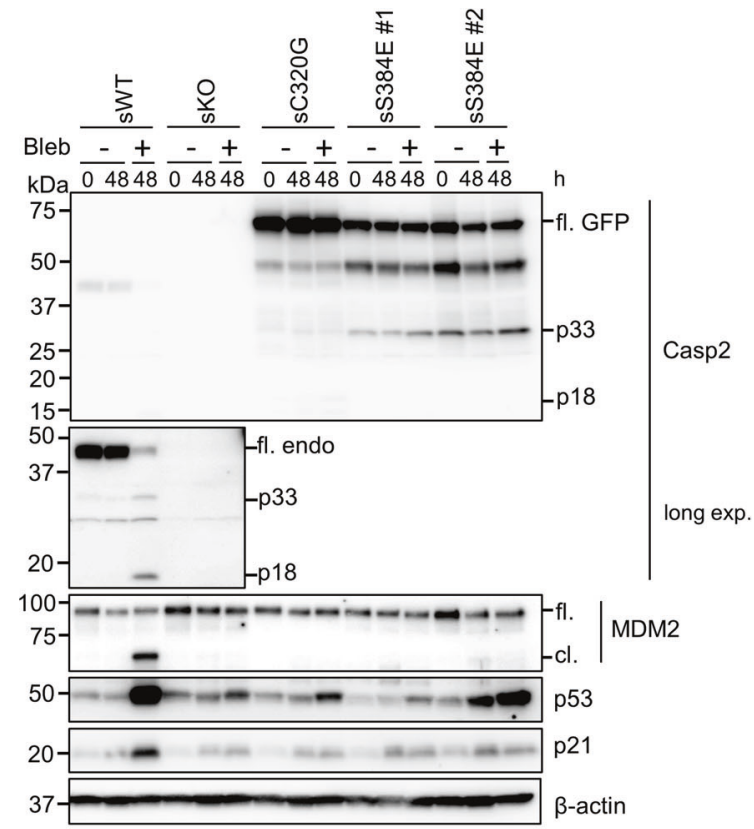

b

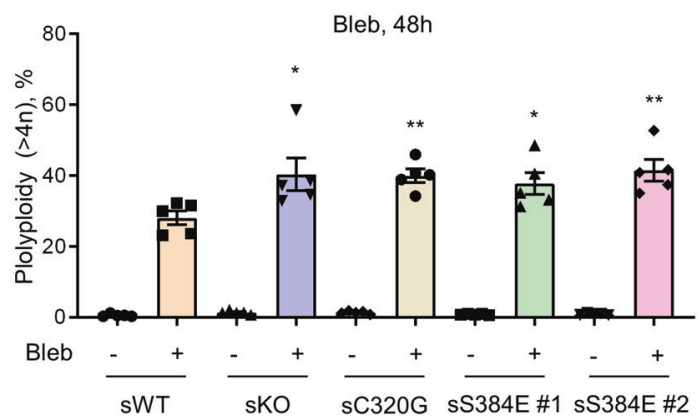

Fig. 6 Caspase-2-S384E expressing cells fail to cleave MDM2 and show increased polyploidy following cytokinesis block with blebbistatin. GFP-expressing U2OS (sWT) and U2OS-CASP2 $2^{-1-}$ expressing GFP (sKO), GFP-caspase-2-C320G (sC320G) or GFPcaspase-2-S384E (sS384 \#1 and \#2), were treated with DMSO or 50 $\mu \mathrm{M}$ blebbistatin (Bleb) for $48 \mathrm{~h}$ and subjected to immunoblot and DNA content analysis. a Representative immunoblots (from five independent experiments) of cell lysates from treated stable cell lines. Antibodies used for immunoblotting are as indicated. $\beta$-actin was used as loading control. b Graph comparing percentage of cells with polyploid $(>4 N)$ DNA content following Bleb treatment. The percentage of polyploid cells $(>4 N)$ was calculated using FACS Express 6 cell cycle analysis module. Mean \pm SEM; $n=5 .{ }^{*} p<0.05 ; * *<0.01$ compared to $s W T+$ Bleb.

dephosphorylate caspase-2 S340 residue, leading to caspase-2 activation and cell death [16, 46]. Therefore, identification of the phosphatase(s) of S384 that can trigger caspase-2 activation may provide an important mechanism to eliminate polyploid cells.

We propose that during normal mitosis caspase- 2 is maintained in an inactive state by both Cdk1 and AURKBmediated phosphorylation until anaphase onset and then a

$\mathrm{BI}, 48 \mathrm{~h}$

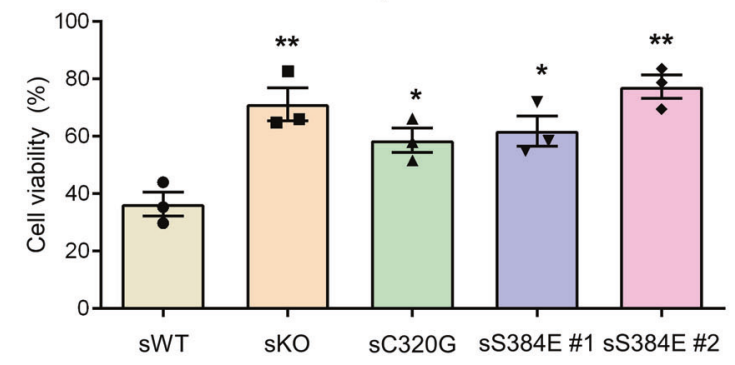

b

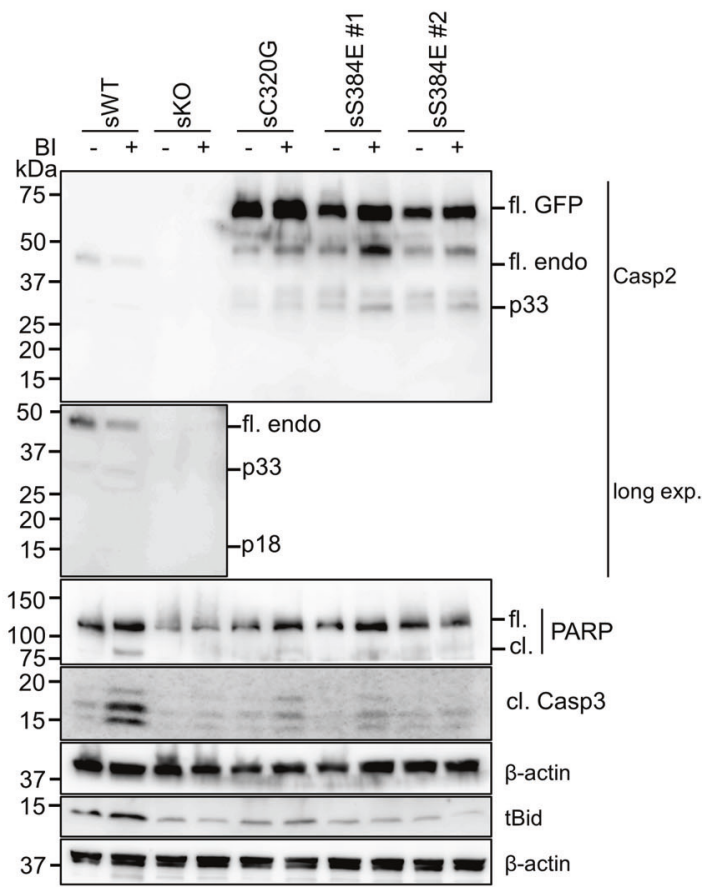

Fig. 7 Caspase-2-S384E expressing cells are resistant to aberrant mitosis-mediated cell death. GFP-expressing U2OS (sWT) and U2OS-CASP2 $2^{-l-}$ expressing GFP (sKO), GFP-caspase-2-C320G (sC320G) or GFP-caspase-2-S384E (sS384 \#1 and \#2), were treated with DMSO or $100 \mathrm{nM}$ BI2536 (BI) for $48 \mathrm{~h}$ and subjected to immunoblot and MTS assay. a Plot showing percentage of viable cells following BI treatment. Mean \pm SEM; $n=3$. * $p<0.05 ; *^{*} p<$ 0.01 compared to sWT. b Representative immunoblots (from three independent experiments) of cell lysates from treated stable cell lines. Antibodies used for immunoblotting are as indicated. $\beta$-actin was used as loading control.

only by AURKB-mediated phosphorylation at S384 until abscission. If $\mathrm{MC}$ is triggered before anaphase, by failure of chromosome alignment for example, inhibition/reduction of Cdk1 and AURKB, and dephosphorylation at both S340 and S384 would activate caspase-2 to promote cell death. If instead there are irrecoverable problems specifically during cytokinesis, such as persistent lagging chromatin, then the inactivation/reduction of AURKB would enable dephosphorylation at S384 to trigger caspase-2 activation and apoptosis (Fig. 8c). Reduced AURKB levels have previously been shown to cause MC as well as premature 
a

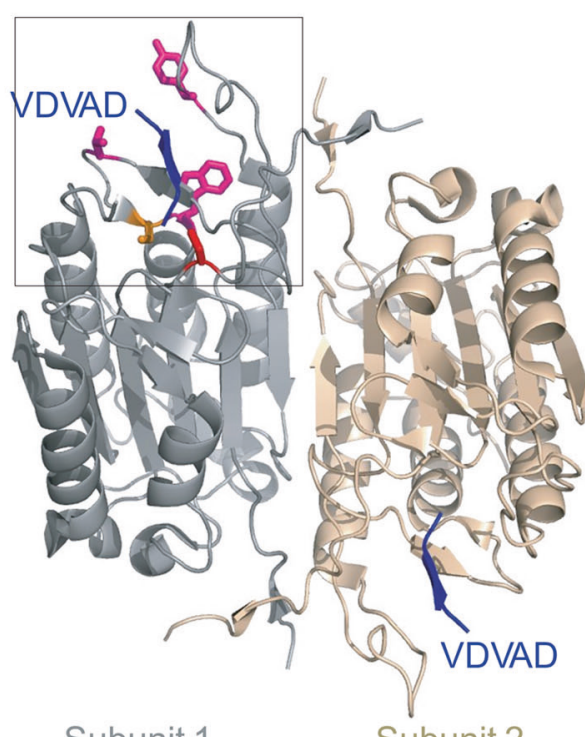

b

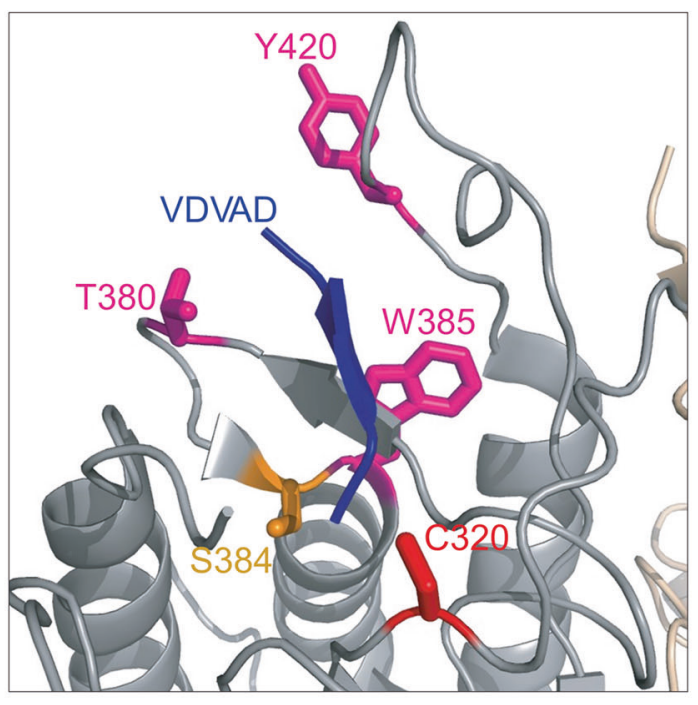

Subunit $1 \quad$ Subunit 2

\section{C}

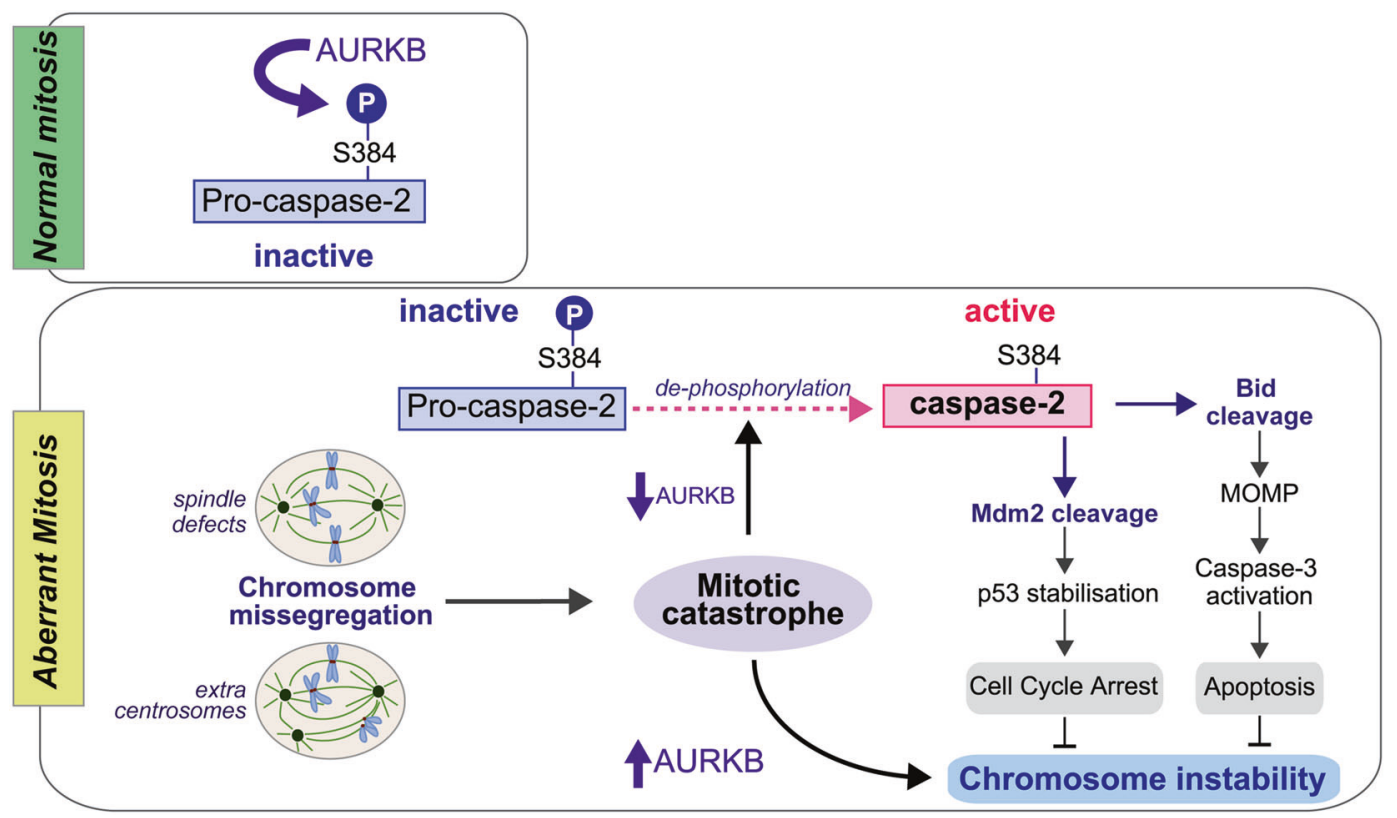

Fig. 8 Phosphorylation at S384 affects the conformation of the substrate binding pocket. a The crystal structure of human active caspase-2/VDVAD (PDB ID: 3R6G) [41] complex. Crystalised caspase-2 is composed of two p19/p12 heterodimers. b Magnified view showing position of S384 and surrounding amino acid residues important for substrate binding. T380 and Y420 and W385 are shown in magenta and interact with P5 and P4 residues [41]. S384 and C320 are shown in orange and red, respectively. c Schematic showing regulation of caspase- 2 by AURKB-mediated phosphorylation in mitosis. During normal mitosis, S384 of caspase-2 is phosphorylated by AURKB, maintaining caspase-2 in inactive state. In response to aberrant mitosis, such as cytokinesis failure and chromosome missegregation, reduced AURKB activity enables S384 dephosphorylation by protein phosphatase(s) (PP). This leads to caspase-2 activation that can result in two outcomes: either cleavage of MDM2, which leads to p53 stabilisation and cell cycle arrest, or cleavage of Bid, which leads to outer mitochondrial membrane permeabilization (MOMP), caspase-3 activation and apoptotic cell death. Increased AURKB levels (and reduced caspase-2 activation) are associated with chromosome instability. Therefore, these caspase-2 activation pathways limit cells becoming aneuploid or polyploid, preventing chromosome instability. Dashed lines indicate unknown mechanisms. 
mitotic exit and we now demonstrate that this directly causes caspase- 2 activation as a mechanism to prevent survival of cells that slip through mitosis and become polyploid.

Overexpression and enhanced kinase activity of AURKB in various tumour types are well documented and associated with therapy resistance and low survival rate in various cancers. Therefore, AURKB is considered as a potential therapeutic target in cancer [47]. Together with our data presented here, this suggests that in tumour cells, AURKB may act to maintain caspase- 2 in a phosphorylated inactive state, thereby preventing apoptotic cell death that contributes to therapy resistance. We therefore propose that the phosphorylation state of caspase-2 may predict apoptosis sensitivity and treatment response in cancer.

Cytokinesis failure induced by AURKB inhibition has previously been shown to induce caspase- 2 activation, MDM2 cleavage and accumulation of p53 and cell cycle arrest in both U2OS and A549 cells [14, 15]. We have also previously observed increased polyploidy in U2OS$C A S P 2^{-1-}$ cells, as a consequence of the accumulation of uncleaved, full-length MDM2, but still associated with increased p53 levels [14]. This suggested the presence of an MDM2-independent p53 response following aberrant mitosis, in caspase-2 deficient cells [14]. In this study, we now demonstrate that, similar to $C A S P 2^{-1-}$ cells or C320G expression, cells stably expressing the caspase-2S384E mutant acquire increased polyploidy associated with lack of MDM2 cleavage. Importantly, we have also observed this, using a different cytokinesis inhibitor, blebbistatin [37], that induces polyploidy. These data confirm that our results are a consequence of general cytokinesis failure and phosphorylation of caspase- 2 at S384 can prevent the canonical MC response and exacerbate polyploidy.

We have previously demonstrated that caspase- 2 activation and its catalytic activity are required for Bidmediated apoptotic cell death of aneuploid cells [12]. Our findings now demonstrate that the caspase-2-S384E cell line does not show Bid cleavage and is more resistant to apoptosis caused by Plk1 inhibition. This further suggests that as well as causing accumulation of MDM2, and dampening p53-mediated cell cycle arrest, the S384E mutant prevents caspase-2-mediated apoptosis.

Taken together, our data suggest that AURKBmediated phosphorylation at S384 of caspase-2 is a critical mechanism that regulates its activation and cellular functions. As activation of caspase- 2 is required following $\mathrm{MC}$ to prevent survival of polyploid cells following failed mitosis and failure to repair damaged DNA [1,3], it will be important to examine in future, whether phosphorylation of caspase-2 at S384 also prevents its tumour suppressor function.

\section{Materials and methods}

\section{Antibodies}

The following antibodies were used: anti-caspase-2 (clone 11B4; produced in-house [48] and available from Merck \#MAB3507); anti-GFP (600-101-215, Rockland, Limerick, PA, USA); anti-MDM2 (OP46, EMD Millipore, Billerica, MA, USA); anti-p53 (sc-126, Santa Cruz Biotechnology, Dallas, TX, USA)); anti-p21 (5567430, BD Bioscience, Franklin Lakes, NJ, USA); anti-PARP (9542, Cell Signalling Technology, Beverly, MA, USA); anti-Bid (2002, Cell Signalling Technology); anti-cleaved caspase-3 (9664, Cell Signalling Technology); anti-HA (H6908, Sigma-Aldrich, St. Louis, MO, USA); anti-GST (G7781, Sigma-Aldrich); anti-Phospho-Histone H3 (9701, Cell Signalling Technology); anti-His (ab18184, Abcam, Cambridge, MA, USA) and anti- $\beta$-actin (A1978, Sigma-Aldrich).

\section{Cell culture and transfection}

U2OS (ATCC, Manassas, VA, USA), U2OS-CASP2 ${ }^{-/-}$, U2OS-CASP2 ${ }^{-1-} / \mathrm{CASP}^{-/-}$, A549, A549-CASP2 $2^{-/}$and stable cell lines were maintained in Dulbecco's Modified Eagles Medium (DMEM, Sigma-Aldrich) supplemented with $10 \%$ foetal bovine serum (JRH Biosciences, Lenexa, KS, USA), $0.2 \mathrm{mM}$ L-glutamine (Sigma-Aldrich), $15 \mathrm{mM}$ HEPES (Sigma-Aldrich) and $100 \mu \mathrm{M}$ penicillin/streptomycin (Sigma-Aldrich) in a humidified incubator at $37^{\circ} \mathrm{C}$ with $10 \% \mathrm{CO}_{2}$. A549 and A549-CASP2 ${ }^{-/-}$cell lines were provided by Prof. Villunger (Medical University of Innsbruck, Austria). Where indicated, cells were treated with $100 \mathrm{nM}$ BI2536 (Axon Medchem, Netherlands), $2 \mu$ M ZM447439 (Sigma-Aldrich), $400 \mathrm{nM}$ AZD1152-HQPA (SigmaAldrich), or $50 \mu \mathrm{M}$ blebbistatin (Selleck Chemicals, Houston, TX, USA) for 24 or $48 \mathrm{~h}$. MEFs were maintained in DMEM (Sigma-Aldrich) supplemented with $0.2 \mathrm{mM}$ L-glutamine (Sigma-Aldrich), $15 \mathrm{mM}$ HEPES (SigmaAldrich), $10 \%$ foetal bovine serum (JRH Biosciences) and $50 \mu \mathrm{M} \beta$-mercaptoethanol (Sigma-Aldrich), non-essential amino acid mix (Sigma-Aldrich), $100 \mu \mathrm{M}$ penicillin/ streptomycin (Sigma-Aldrich). Cells were cultured in a humidified incubator at $37^{\circ} \mathrm{C}$ with $10 \% \mathrm{CO}_{2}$. Transfection of plasmid DNA was performed using Lipofectamine 3000 (Life Technologies, Carlsbad, CA, USA) according to the manufacturer's instructions. All cell lines were tested for mycoplasma contamination.

\section{Cloning of caspase-2 phospho site mutants and other constructs}

All phosphorylation site mutants were generated by QuikChange site-directed mutagenesis of pEGFP-mouse caspase-2 
WT [49] or pcDNA-DEST47-mouse caspase-2-WT (for T161A) as PCR template. All primer sequences are outlined in Supplementary Table S1. To produce BiFC-caspase-2S384E constructs, the caspase-2-S384E was amplified from the pEGFP-caspase-2-S384E using the following PCR primers: VN-caspase-2-S384E (forward: 5'-AAAGATCTCGC GGCGCCGAGCGGGAG-3' and reverse: 5'-AATCTAGA CGTGGGTGGGTAGCCTGG- $3^{\prime}$ with added BgIII and XbaI site); VC-caspase-2-S384E (forward: 5'-AAAGATCTCCGC GGCGCCGAGCGGGAG-3' and reverse: 5'-AACTCGAG TCGTGGGTGGGTAGCCTGG-3' with added BgIII and XhoI site). The amplified fragments were cut with $\mathrm{BglII} / \mathrm{XbaI}$ or BglII/XhoI and subsequently subcloned in-frame into pBiFC-VN173 and pBiFC-VC155 (gifts from Lisa BouchierHayes, Baylor College of Medicine, Houston, TX, USA), respectively. For bacterial expression, pGEX4T3-caspase-2WT [27] was used as a template for PCR-based mutagenesis to introduce the S384E, S384A or C320G mutations, followed by insertion into the BamHI and XhoI sites of pGEX4T3. To obtain the small fragment of caspase-2 containing S384 (Casp2 $363-423$-WT or -S384A), the corresponding fragments (aa 363-423) were amplified from the pGEX4T3-caspase-2-WT or -S384A using the following PCR primers: (forward: 5'-AAAGGATCCGACATGAT ATGTGGCTATGCTTG- $3^{\prime}$ and reverse: 5'-AAACTCGAG TTAGCCAGGGGCATAG CCTTC- $3^{\prime}$ ) and subcloned into pGEX-4T-3 using BamHI and XhoI sites. To obtain human AURKB expression plasmid construct, full-length AURKB was amplified from CDNA made from U2OS cells using the following PCR primers: (forward: 5'-AAACATATGG CCCAGAAGGAGAACTCC- $3^{\prime}$ and reverse: 5'-AAACTCG AG GGCGACAGATTGAAGGGC-3') and subcloned into pET-32a vector plasmid via NdeI and XhoI sites. Each construct was confirmed by DNA restriction enzyme digestion and DNA sequencing. All DNA restriction enzymes were purchased from NEB (Ipswich, MA, USA).

\section{Expression and purification of recombinant proteins}

The plasmids pGEX4T3-caspase-2-WT, -S384E or -S384A, pGEX4T3-Casp2 2363-423 (WT or S384A) or pET-32aAURKB were transformed into E. coli BL21(DE3)pLysS (Promega, Madison, WI, USA). Single colonies were inoculated into $50 \mathrm{~mL}$ LB with $100 \mu \mathrm{g} / \mathrm{mL}$ ampicillin and cultured overnight at $37^{\circ} \mathrm{C}$ with shaking at $180-200 \mathrm{rpm}$. The next day, $10 \mathrm{~mL}$ overnight culture was diluted into $400 \mathrm{~mL} \mathrm{LB}$ with ampicillin $(100 \mu \mathrm{g} / \mathrm{mL})$ and cultured at $30{ }^{\circ} \mathrm{C}$. To induce recombinant proteins isopropyl- $\beta$-Dthiogalactoside (IPTG, Sigma-Aldrich) was added $(0.1 \mathrm{mM})$ when $\mathrm{OD}_{600}$ was between 0.4 and 0.6 and the culture was incubated for $24 \mathrm{~h}$ at $16^{\circ} \mathrm{C}$. Bacterial cells were harvested by centrifugation at $5000 \mathrm{rpm}$ for $10 \mathrm{~min}$ at $4{ }^{\circ} \mathrm{C}$. For GSTtagged recombinant protein purification, the pellet was resuspended in $20 \mathrm{~mL}$ of cold lysis buffer ( $25 \mathrm{mM}$ HEPES, $10 \%$ sucrose, $0.1 \%$ CHAPS, $1 \mathrm{mM}$ EDTA, $10 \mathrm{mM}$ DTT, $\mathrm{pH}$ 7.4) with protease inhibitor (Sigma-Aldrich), followed by sonication $(10 \times 20$-s pulses). Triton X-100 (SigmaAldrich) was then added to a final concentration $0.1 \%$ and incubated for $1 \mathrm{~h}$ at $4{ }^{\circ} \mathrm{C}$ with rocking, followed by centrifugation at $15000 \mathrm{rpm}$ for $30 \mathrm{~min}$ at $4^{\circ} \mathrm{C}$. Supernatant was transferred to a new $50 \mathrm{~mL}$ falcon tube and $250 \mu \mathrm{L}$ bed volume of PBS-washed glutathione Sepharose beads (GE Healthcare Australia) was added to the lysate, followed by overnight incubation at $4{ }^{\circ} \mathrm{C}$ with rocking. Supernatant containing beads were transferred to a column in a $4^{\circ} \mathrm{C}$ cold room and flow through was collected. Beads were then washed four times with $10 \mathrm{~mL}$ PBST (PBS, $0.1 \%$ Triton X100). GST-tagged recombinant protein was eluted in 10 bead volumes of elution buffer $(50 \mathrm{mM}$ Tris, $10 \mathrm{mM}$ reduced glutathione, $\mathrm{pH}$ 8.0) in 10 fractions. For AURKB purification, bacterial pellet was resuspended in $20 \mathrm{~mL}$ of cold His-lysis buffer $\left(50 \mathrm{mM} \mathrm{NaH} \mathrm{PO}_{4}, 300 \mathrm{mM} \mathrm{NaCl}\right.$, $10 \mathrm{mM}$ imidazole, $\mathrm{pH}$ 8.0) with protease inhibitor (SigmaAldrich), followed by sonication $(10 \times 20$-second pulses $)$ and centrifugation at $15000 \mathrm{rpm}$ for $30 \mathrm{~min}$ at $4{ }^{\circ} \mathrm{C}$. The supernatant was transferred to a new $50 \mathrm{~mL}$ falcon tube and $250 \mu \mathrm{L}$ bed volume of Ni-Sepharose (GE Healthcare, Waukesha, WI, USA) was added to the lysate, followed by overnight incubation at $4{ }^{\circ} \mathrm{C}$ with rocking. Lysate containing beads were transferred to a column in the cold room and flow-through was collected. Beads were washed four times with $10 \mathrm{~mL}$ of wash buffer $\left(50 \mathrm{mM} \mathrm{NaH} \mathrm{NO}_{4}, 300 \mathrm{mM}\right.$ $\mathrm{NaCl}, 20 \mathrm{mM}$ imidazole, $\mathrm{pH}$ 8.0). His-AURKB was eluted in 10 bead volumes of elution buffer $\left(50 \mathrm{mM} \mathrm{NaH}_{2} \mathrm{PO}_{4}\right.$, $300 \mathrm{mM} \mathrm{NaCl}, 250 \mathrm{mM}$ imidazole, $\mathrm{pH}$ 8.0) and collected in 10 fractions. Purified proteins were checked by SDS-PAGE analysis. Pooled eluates were dialysed against $50 \mathrm{mM}$ Tris$\mathrm{HCl}, \mathrm{pH}$ 7.5. Protein concentration was quantitated with BCA Protein Assay (Thermo Fisher Scientific, Rockford, IL, USA) and stored in aliquots at $-80^{\circ} \mathrm{C}$ until used.

\section{Purification of caspase-2-C320G-GFP}

U2OS-CASP2 $2^{-/-}$cells were seeded into $16 \times 100 \mathrm{~mm}$ dishes at a total density of $1.5 \times 10^{6}$ cells/dish. Cells were treated with $20 \mu \mathrm{M} \mathrm{Z-VAD}$ for $2 \mathrm{~h}$ and then transfected with $6 \mu \mathrm{g}$ pEGFP-caspase-2-C320G for $48 \mathrm{~h}$. The cells were harvested and lysed in RIPA buffer $[25 \mathrm{mM}$ Tris- $\mathrm{HCl} \mathrm{pH}$ 7.4, $150 \mathrm{mM} \mathrm{NaCl}, 1 \%$ nonyl-phenoxylpolyethoxylethanol (NP-40), $1 \%$ sodium deoxycholate, $0.1 \%$ sodium dodecyl sulfate (SDS)] supplemented with 1X Halt Protease and Phosphatase Inhibitor Cocktail, EDTA (Thermo Fisher Scientific), and $10 \mu \mathrm{M}$ N-ethylmaleimide (Sigma-Aldrich). Lysed cells were sonicated, and lysates cleared by centrifugation at $13200 \mathrm{rpm}\left(4^{\circ} \mathrm{C}\right)$. GFP-Trap (ChromoTek, Germany) was used to purify caspase-2-C320G-GFP, 
according to the manufacturer's instruction. Briefly, $150 \mu \mathrm{L}$ GFP-Trap_MA bead suspension was equilibrated by washing with RIPA buffer three times. Cell lysates were added to the GFP-Trap_MA beads and incubated at $4{ }^{\circ} \mathrm{C}$ overnight with gentle rocking. The beads were then separated magnetically until the supernatant was clear. The supernatant was collected as 'flow-through' sample for SDS-PAGE and western blot analysis. The beads were resuspended in $1 \mathrm{~mL}$ ice-cold wash buffer $(10 \mathrm{mM}$ Tris$\mathrm{HCl}, 150 \mathrm{mM} \mathrm{NaCl}, 0.5 \mathrm{mM}$ EDTA, pH 7.5), briefly spun and magnetically separated. The supernatant was removed, and washing was repeated four more times with high salt wash buffer $(10 \mathrm{mM}$ Tris- $\mathrm{HCl}, 500 \mathrm{mM} \mathrm{NaCl}, 0.5 \mathrm{mM}$ EDTA, pH 7.5). Bound GFP-caspase-2-C320G was eluted by adding $50 \mu \mathrm{L}$ elution buffer $(0.2 \mathrm{M}$ glycine $\mathrm{pH} 2.5)$, followed by incubation for $2 \mathrm{~min}$ and magnetic separation. The supernatant was transferred to a new tube and $5 \mu \mathrm{L}$ of 1 M Tris (pH 10.4) was added for neutralisation. Elution was repeated three times. A sample of each fraction $(10 \mu \mathrm{L})$ was subjected to SDS-PAGE analysis and Coomassie blue staining (Supplementary Fig. S1). 'Elution 1' was utilised for proteomic analysis.

\section{Mass spectrometry and data analysis}

Protein samples were resuspended in $6 \mathrm{M}$ urea, $100 \mathrm{mM}$ DTT and $100 \mathrm{mM}$ Tris- $\mathrm{HCl}(\mathrm{pH}$ 7.0) and subjected to protein digestion using FASP (filter aided sample preparation) [50]. Peptides were collected and acidified with formic acid (FA) to a $1 \%$ final concentration. Solvent was removed in a CentriVap concentrator (Labconco, Kansas, MO, USA) and peptides were resuspended in Milli-Q water containing $1 \%$ acetonitrile $(\mathrm{ACN})$ and $1 \%$ FA. Samples were analyzed by nanoflow LC-MS/MS on a nanoAcquity system (Waters, Milford, MA, USA) coupled to a Q-Exactive Mass Spectrometer (Thermo Fisher Scientific) through a nanoelectrospray ion source (Thermo Fisher Scientific). Peptide mixtures were directly loaded onto a $250 \mathrm{~mm}$ column with $75 \mu \mathrm{m}$ inner diameter (nanoAcquity UPLC $1.7 \mu \mathrm{m}$ BEH130 C18) on a 120 min linear gradient from 1 to $35 \%$ buffer B (A: $99.9 \%$ Milli-Q water, $0.1 \%$ FA; B: $99.9 \%$ ACN, $0.1 \%$ FA) at a $400 \mathrm{~nL} / \mathrm{min}$ constant flow rate. The Q-Exactive was operated in a data-dependent mode, switching automatically between one full-scan and subsequent MS/MS scans of the ten most abundant peaks. The instrument was controlled using Exactive series version 2.6 and Xcalibur 3.0. Fullscans $(\mathrm{m} / \mathrm{z}, 350-1850)$ were acquired with a resolution of 70000 at $200 \mathrm{~m} / z$. The ten most intense ions were sequentially isolated with a target value of 10000 ions and an isolation width of $3 \mathrm{~m} / \mathrm{z}$ and fragmented using HCD with normalized collision energy of 27 and stepped collision energy of $15 \%$. Maximum ion accumulation times were set to $50 \mathrm{~ms}$ for full MS scan and $200 \mathrm{~ms}$ for MS/MS. Underfill ratio was set to $2 \%$ and dynamic exclusion was enabled and set to $60 \mathrm{~s}$.

The raw files were analysed using the MaxQuant [51, 52] software (version 1.5.8.3). The database search was performed using mouse protein sequences obtained from Uniprot including isoforms with strict trypsin specificity allowing up to two missed cleavages. The minimum required peptide length was set to seven amino acids. Carbamidomethylation of cysteine was set as a fixed modification while $\mathrm{N}$-acetylation of proteins $\mathrm{N}$-termini, oxidation of methionine, phosphorylation of S/T/Y and GlyGly on lysine were set as variable modifications. During the MaxQuant main search, precursor ion mass error tolerance was set to $4.5 \mathrm{ppm}$ and fragment ions were allowed a mass deviation of $20 \mathrm{ppm}$. PSM and protein identifications were filtered using a target-decoy approach at a false discovery rate of $1 \%$.

\section{Protein pull-down assays}

To examine the direct interaction between caspase- 2 and AURKB, GST pull-down assay was carried out. GST, GSTCasp2-C320G or GST-Casp2 363-423-WT $(1 \mu \mathrm{g})$ was incubated with $500 \mathrm{ng}$ His-AURKB in $300 \mu \mathrm{L}$ incubation buffer (50 mM Tris-HCl, $10 \mathrm{mM} \mathrm{MgCl} 2,0.1 \mathrm{mM}$ EDTA, $0.01 \%$ Brij 35, $\mathrm{pH}$ 7.5) for $2 \mathrm{~h}$ with rotation, at room temperature. This was followed by addition of $10 \mu \mathrm{L}$ glutathione-agarose beads (GE Healthcare) and further incubation for $1 \mathrm{~h}$ with rotation at room temperature. After four washes with incubation buffer, beads were heated in $2 x$ Laemmli buffer for $5 \mathrm{~min}$ at $95^{\circ} \mathrm{C}$. Samples and $10 \%$ inputs were then subjected to SDS-PAGE and IB.

To examine the interaction between caspase- 2 and AURKB in cells, U2OS-CASP2 ${ }^{-/-}$cells stably expressing GFP (sKO) or GFP-Casp2-C320G (sC320G) were used. For mitotic cells, sC320G cells were synchronized in $\mathrm{G} 1 / \mathrm{S}$ by treatment with $2 \mathrm{mM}$ thymidine (Sigma-Aldrich) for $24 \mathrm{~h}$. After washing with PBS, the cells were released into complete media for $3 \mathrm{~h}$, followed by treatment with $100 \mathrm{ng} / \mathrm{mL}$ nocodazole (Sigma-Aldrich) for $14 \mathrm{~h}$. Mitotic cells were collected by gentle shaking of the culture flasks. For AURKB inhibition, sC320G cells were treated with AURKB inhibitor, ZM447439 (ZM, $2 \mu \mathrm{M}$ ) for $24 \mathrm{~h}$. The cells were lysed in NP40 lysis buffer ( $150 \mathrm{mM} \mathrm{NaCl}, 1 \% \mathrm{NP}-40,50 \mathrm{mM}$ Tris-HCl, pH 8.0) containing 1X Halt Protease and Phosphatase Inhibitor Cocktail, EDTA (Thermo Fisher Scientific). The cell lysates were then incubated with GFP-Trap for $2 \mathrm{~h}$ at $4{ }^{\circ} \mathrm{C}$ with gentle rocking, followed by four washes in lysis buffer. Bound GFP or GFP-caspase-2-C320G was eluted by adding $25 \mu \mathrm{L}$ elution buffer $(0.2 \mathrm{M}$ glycine, $\mathrm{pH} 2.5)$ as described above. The pooled elutes were neutralised by adding $5 \mu \mathrm{L}$ of $1 \mathrm{M}$ Tris (pH 10.4) and subjected to IB. Forty micrograms of the cell lysates were used as input. 


\section{Caspase-2 dimerisation assay}

BiFC analysis for caspase-2 activation was performed as described previously with minor modifications [53]. Briefly, U2OS-CASP $2^{-1-}$ cells were seeded onto $13 \mathrm{~mm}$ glass coverslips (Thermo Fisher Scientific) and incubated overnight at $37{ }^{\circ} \mathrm{C}$ in a $10 \% \mathrm{CO}_{2}$ incubator. The next day, the medium was replaced with complete culture medium containing $20 \mu \mathrm{M}$ Z-VAD-FMK (Sigma-Aldrich) $2 \mathrm{~h}$ prior to transfection. The cells were then co-transfected with $150 \mathrm{ng}$ of the pBiFC-HA-Casp2(S384E)-VC155 and pBiFC-HACasp2(S384E)-VN173 (mouse caspase-2) for BiFC and 10 ng of pDsRed-Mito (Clontech, Takara Bio USA, Mountain View, CA, USA) as a transfection reporter plasmid, using Fugene HD reagent (Promega). pBiFC-HA-CASP2 (C320A)-VC155 and pBiFC-HA-CASP2 (C320A)-VN173 (human caspase-2) were used as system control [12]. After incubation for $2 \mathrm{~h}$, DMSO (control) or $100 \mathrm{nM} \mathrm{BI} 2536$ (Sigma-Aldrich) was added to the medium and cells were incubated a further $24 \mathrm{~h}$ at $37^{\circ} \mathrm{C}$ in a $10 \% \mathrm{CO}_{2}$ incubator. Cells were then fixed with $4 \%$ paraformaldehyde (SigmaAldrich) in PBS and BiFC imaged by confocal microscopy using a Leica TCS SP8 (Leica, Wetzlar, Germany). At least 100 cells were counted in five different areas in two independent experiments to quantify BiFC-positive cells.

\section{Caspase activity assay}

Caspase activity assay using VDVAD-AFC was carried out as previously described [54]. The protein concentration of cell lysates were quantified by BCA Protein Assay (Thermo Fisher Scientific) according to the manufacturer's instructions and $50 \mu \mathrm{g}$ of cell lysate was mixed with caspase-2 activity buffer (0.1 M MES [2-(N-morpholino) ethanesulfonic acid], $10 \%$ sucrose, $0.1 \%$ CHAPS, $0.5 \mathrm{mM}$ EDTA, $\mathrm{pH} 6.5)$ to a total volume of $50 \mu \mathrm{L}$. VDVAD-AFC $(100 \mu \mathrm{M}$, Sigma-Aldrich)) diluted in $50 \mu \mathrm{L}$ of caspase-2 activity buffer was added to each sample to give a final volume of $100 \mu \mathrm{L}$ per well. Fluorescence was measured in $10 \mathrm{~min}$ intervals for $170 \mathrm{~min}$ at $37^{\circ} \mathrm{C}$, with excitation $=400 \mathrm{~nm}$, emission $=505 \mathrm{~nm}$, to quantitate caspase- 2 activity. For GST recombinant proteins, $20 \mu \mathrm{L}$ of crude $E$. coli extract was used.

\section{Generation of KO cell lines}

U2OS-Caspase-2 KO (U2OS-CASP2 ${ }^{-/-}$) cell line was generated using CRISPR/Cas9 technology as described previously [55]. pSpCas9(BB)-2A-Puro (PX459) was a gift from Feng Zhang (Addgene plasmid \#48139; http://n2t. net/addgene:48139; RRID:Addgene_48139) [55]. The sgRNA oligos (sense: $5^{\prime}$-caccgaccaaaaatgttcttcatcc-3'; antisense: $5^{\prime}$-aaacggatgaagaacattttggtc- $3^{\prime}$ ) were annealed, phosphorylated by T4 PNK (NEB) and inserted into BbsI (NEB) site of pSpCas9(BB)-2A-Puro (PX459) vector plasmid. To establish the KO cell line, $2 \times 10^{5}$ U2OS cells were transfected with $2 \mu \mathrm{g}$ of sgRNA and Cas 9 expressing plasmid using Fugene HD reagent (Promega) according to the manufacturer's instruction. pSpCas9(BB)-2A-GFP and pSpCas9 (BB)-2A-Puro (PX459) were also transfected as a negative control and positive control, respectively, for puromycin treatment. The cells were treated with $1 \mu \mathrm{g} / \mathrm{mL}$ puromycin for 2 days until all negative control cells had died. The surviving cells were harvested and re-seeded into three $10 \mathrm{~cm}$ dishes at $1 \times 10^{3}$ cells/dish for isolating single colonies. To screen candidate single clones, the sgRNA-targeted area was amplified by PCR (forward: 5'-tggtggaagccaactgttgaaacc-3'; reverse: $5^{\prime}$ - tctcagaaaggaaggcaaagacacg- $3^{\prime}$ ) and the PCR products were analysed by heteroduplex analysis in PAGE gel as described previously [56] and DNA sequencing. DNA sequencing results were used for insertion and deletion analysis in the targeted gene area by TIDE software (http://tide. nki.nl). Loss of caspase- 2 expression in the candidate clones was validated by western blot.

The U2OS-CASP2 ${ }^{-/-} / C A S P 3^{-/-}$cell line was generated using one of the U2OS-CASP2 $2^{-1-}$ clones, as above. The sgRNA oligos (sense: $5^{\prime}$-caccgattatacataaacccatctc-3'; antisense: $5^{\prime}$-aaacgagatgggtttatgtataatc- $3^{\prime}$ ) used for cloning into pSpCas9(BB)-2A-Puro (PX459) vector plasmid. The sgRNA-targeted area was amplified by PCR (forward: $5^{\prime}$ gcctcacgtcaggtcattt--3'; reverse: $5^{\prime}$-tgtaggtcctgcccaatctc- $3^{\prime}$ ) for genetic analyses. Western blot was performed to validate loss of caspase- 3 expression.

\section{Immunofluorescence microscopy}

U2OS cells stably expressing GFP (sWT) and U2OS$\mathrm{CASP}^{-/-}$cells stably expressing GFP (sKO), GFP-Casp2C320G (sC320G) or GFP-Casp2-S384E (sS384E) were generated using pEGFP mock, pEGFP-Casp2-C320G or pEGFP-Casp2-S384E plasmids, respectively. For immunofluorescence microscopy, cells were grown on coverslips overnight and fixed in 4\% paraformaldehyde in PBS for 10 min at room temperature. The fixed cells were washed in TBS, permeabilized and blocked with blocking solution (3\% BSA, $0.1 \%$ Triton $\mathrm{X}-100$ in TBS) for $1 \mathrm{~h}$ at RT. Samples were incubated overnight with goat anti-GFP antibody at 1:500 dilution in blocking solution. After three washes in TBS/0.1\% Triton X-100, coverslips were incubated for $60 \mathrm{~min}$ with anti-goat IgG-Alexa568 (Molecular Probes, Thermo Fisher Scientific) diluted in blocking solution. Samples were washed another three times (as above) and coverslips were mounted onto glass slides with mounting medium containing DAPI (Life Technologies). Images were taken with a Zeiss LSM-800 confocal microscope (Zeiss, Germany). 


\section{Immunoblotting}

Protein samples were denatured for $5 \mathrm{~min}$ at $95^{\circ} \mathrm{C}$ and run on Mini or Midi TGX Stain-Free Precast Gels (Bio-Rad, Hercules, CA, USA) at $110 \mathrm{~V}$ for $60 \mathrm{~min}$ (mini gels) or at $140 \mathrm{~V}$ for $60 \mathrm{~min}$ (midi gels) in SDS-PAGE running buffer (250 mM Tris, $192 \mathrm{mM}$ glycine, $0.06 \%$ SDS). The proteins were transferred onto PVDF membrane (Bio-Rad) using a Trans-Blot Turbo (Bio-Rad), according to the manufacturer's instructions, in transfer buffer (25 mM Tris, 192 $\mathrm{mM}$ glycine, $20 \%$ methanol, $0.05 \%$ SDS). Membranes were then incubated in blocking buffer [TBST (20 mM Tris, 150 $\mathrm{mM} \mathrm{NaCl} \mathrm{pH} 7.4,0.05 \%$ Tween- 20)], 5\% (w/v) skim milk powder (Diploma) for $1 \mathrm{~h}$ at $\mathrm{RT}$, followed by incubation with primary antibody overnight at $4{ }^{\circ} \mathrm{C}$. Following membrane washing in TBST for $4 \times 15 \mathrm{~min}$, membranes were incubated with horse radish peroxidase (HRP)-conjugated secondary antibodies for $1 \mathrm{~h}$ at RT. Membranes were then washed in TBST for $4 \times 10 \mathrm{~min}$, followed by development with Enhanced Chemiluminescence reagent (Pierce Chemical Co., Rockford, IL, USA). Fuji LAS4000 System (GE Healthcare) or ChemiDoc MP (Bio-Rad) were used for detecting luminescence signals.

\section{DNA content analysis}

DNA content analysis was performed as described previously [14]. Briefly, harvested cells were washed with icecold 1X PBS followed by fixation in 70\% ice-cold ethanol in PBS. Fixed cells were incubated overnight at $-20^{\circ} \mathrm{C}$. Cells were centrifuged at $1200 \mathrm{rpm}$ for $5 \mathrm{~min}$ then resuspended in $2 \mathrm{~mL} 1 \mathrm{X}$ PBS for rehydration. Cells were centrifuged a second time and pellets resuspended in $1 \mathrm{~mL}$ 0.25\% Triton X-100 (Sigma-Aldrich) in PBS. Following a final centrifugation step, cell pellets were resuspended in $400 \mu \mathrm{L}$ staining solution $[25 \mu \mathrm{g} / \mathrm{mL}$ propidium iodide (Sigma-Aldrich), $40 \mu \mathrm{g} / \mathrm{mL}$ RNase A (Sigma-Aldrich)] and incubated for $2 \mathrm{~h}$ at room temperature in the dark. The stained cells were stored at $4{ }^{\circ} \mathrm{C}$ until flow cytometric analysis on a Fortessa (BD Biosciences). For data in Fig. 5b, Fig. 6b and Supplementary Fig. S7b, approximately 25000 cells were anlased and the percentage of polyploid cells $(>4 N)$ was calculated using FACS Express 6 cell cycle analysis module.

\section{Cell death and viability assay}

For cell death assays, WT or Casp $2^{-1-}$ immortalised MEFs [11] were co-transfected with GFP-caspase-2-WT, -S384A or -S384E and $\beta$-gal expressing plasmids. After $24 \mathrm{~h}$, cells were fixed and incubated with an X-gal containing solution. Blue (transfected) cells were counted for apoptotic morphology with a stereomicroscope (Nikon, Tokyo, Japan). At least 300-400 cells were counted in at least 20 different fields for each construct. Cell viability was determined using the MTS assay. Briefly, cells were seeded in triplicate at 5000 cells per well in $50 \mu \mathrm{L}$ complete culture media in a 96-well microplate (BD Biosciences) and cultured overnight at $37{ }^{\circ} \mathrm{C}$ with $10 \% \mathrm{CO}_{2}$. Culture medium $(50 \mu \mathrm{L})$ containing DMSO or $200 \mathrm{nM}$ BI2536 was added, followed by $48 \mathrm{~h}$ incubation at $37^{\circ} \mathrm{C}$ with $10 \% \mathrm{CO}_{2}$. Twenty-five microliters of MTS/PMS (96:4) reagent was added to each well. The plate was then incubated in a humidified, $10 \% \mathrm{CO}_{2}$ incubator for $4 \mathrm{~h}$, followed by reading absorbance at $490 \mathrm{~nm}$ using a FLUOstar Omega (BMG Labtech, Ortenberg, Germany). Control wells (no cells), were used to detect the cell-free background absorbance.

\section{In vitro kinase assay}

In vitro kinase assays were performed as described previously [57]. Proteins were incubated with $38 \mathrm{ng}$ of Aurora B kinase (PV6130 Life Technologies) or $125 \mathrm{ng}$ of Aurora A kinase (PV3612 Life Technologies), $0.1 \mathrm{mM}$ ATP (Sigma-Aldrich), $5 \mu \mathrm{Ci}$ of $\left[\gamma^{-}{ }^{32} \mathrm{P}\right]-\mathrm{ATP}(3000 \mathrm{Ci} / \mathrm{mmol}$, $10 \mathrm{mCi} / \mathrm{mL}$ ) (PerkinElmer, Waltham, MA, USA) in kinase buffer (20 mM HEPES [pH 7.5], 2 mM MgCl $2,1 \mathrm{mM} \mathrm{DTT)}$ in a final reaction volume of $12.5 \mu \mathrm{L}$. After $30 \mathrm{~min}$ incubation at $30^{\circ} \mathrm{C}$ with constant agitation, $12.5 \mu \mathrm{L}$ of $2 \mathrm{x}$ Laemmli sample buffer were added to stop the reaction. Samples were heated for $10 \mathrm{~min}$ at $90{ }^{\circ} \mathrm{C}$ and loaded on a 4-20\% Tris-Glycine Precast Gel (Thermo Fisher Scientific). Protein was transferred onto a nitrocellulose membrane using the iBlot Dry Blotting System. Membranes were then exposed to Kodak BioMax XAR Films (Sigma-Aldrich) at $-80^{\circ} \mathrm{C}$. The membranes were then blocked and subjected to IB for GST.

\section{Statistical analysis}

The data are presented as mean \pm standard error of the mean (SEM) and were considered statistically significant when $p<0.05$. A two-sided Student's $t$ test was used to analyse differences between data groups unless otherwise stated. All statistical analyses were conducted using GraphPad Prism, Version 6.05 (GraphPad, supplied by University of South Australia; GraphPad Inc., CA, USA).

\section{Data availability}

The mass spectrometry proteomics data have been deposited to the ProteomeXchange Consortium via the PRIDE [58] partner repository with the dataset identifier PXD017866, and are available via ProteomeXchange. 
Acknowledgements We thank J. Puccini for helping generate the U2OS-CASP2 ${ }^{-1-}$ cell line, A. Villunger for A549 and A549$C A S P 2^{-I-}$ cell lines, CCB Cytometry for DNA content analysis, and members of our laboratory for discussions and useful comments. This project was supported by the National Health and Medical Research Council (NHMRC) of Australia project grants 1043057 and 1156601, an NHMRC Senior Principal Research Fellowship (1103006) and a University of South Australia support package to SK. We acknowledge the support of the Australian Cancer Research Foundation funded Cancer Genomics and Imaging Core Facilities at CCB. JMM acknowledges the NHMRC fellowship (1105754, 1172929) support; JJS, AIW and JMM acknowledge NHMRC IRIISS (9000587); and the work in PPD laboratory is supported by a BBSRC grant (BB/ R001227/1).

Author contributions YL designed and performed experiments, analysed data and wrote the paper; DDB helped with the generation of mutants and performed cell biology experiments; JJS and AIW carried out MS analysis; LC and PPD'A performed in vitro phosphorylation and IB experiments; JMM generated the caspase-2 structure modelling; LD and SK designed and supervised the study, analyzed data, acquired funding and wrote the paper. All authors discussed the results and commented on the manuscript.

\section{Compliance with ethical standards}

Conflict of interest The authors declare that they have no conflict of interest.

Publisher's note Springer Nature remains neutral with regard to jurisdictional claims in published maps and institutional affiliations.

Open Access This article is licensed under a Creative Commons Attribution 4.0 International License, which permits use, sharing, adaptation, distribution and reproduction in any medium or format, as long as you give appropriate credit to the original author(s) and the source, provide a link to the Creative Commons license, and indicate if changes were made. The images or other third party material in this article are included in the article's Creative Commons license, unless indicated otherwise in a credit line to the material. If material is not included in the article's Creative Commons license and your intended use is not permitted by statutory regulation or exceeds the permitted use, you will need to obtain permission directly from the copyright holder. To view a copy of this license, visit http://creativecommons. org/licenses/by/4.0/

\section{References}

1. Vitale I, Galluzzi L, Castedo M, Kroemer G. Mitotic catastrophe: a mechanism for avoiding genomic instability. Nat Rev Mol Cell Biol. 2011;12:385-92.

2. D'Avino PP, Capalbo L. New auroras on the roles of the chromosomal passenger complex in cytokinesis: implications for cancer therapies. Front Oncol. 2015;5:221.

3. Galluzzi L, Vitale I, Aaronson SA, Abrams JM, Adam D, Agostinis P, et al. Molecular mechanisms of cell death: recommendations of the Nomenclature Committee on Cell Death 2018. Cell Death Differ. 2018;25:486-541.

4. Hanahan D, Weinberg RA. Hallmarks of cancer: the next generation. Cell. 2011;144:646-74.

5. Kumar S, Kinoshita M, Noda M, Copeland NG, Jenkins NA. Induction of apoptosis by the mouse Nedd 2 gene, which encodes a protein similar to the product of the Caenorhabditis elegans cell death gene ced-3 and the mammalian IL-1 beta-converting enzyme. Genes Dev. 1994;8:1613-26.

6. Ho LH, Taylor R, Dorstyn L, Cakouros D, Bouillet P, Kumar S. A tumor suppressor function for caspase-2. Proc Natl Acad Sci USA. 2009;106:5336-41.

7. Shalini S, Nikolic A, Wilson CH, Puccini J, Sladojevic N, Finnie $\mathrm{J}$, et al. Caspase-2 deficiency accelerates chemically induced liver cancer in mice. Cell Death Differ. 2016;23:1727-36.

8. Terry MR, Arya R, Mukhopadhyay A, Berrett KC, Clair PM, Witt $\mathrm{B}$, et al. Caspase-2 impacts lung tumorigenesis and chemotherapy response in vivo. Cell Death Differ. 2015;22:719-30.

9. Puccini J, Shalini S, Voss AK, Gatei M, Wilson CH, Hiwase DK, et al. Loss of caspase-2 augments lymphomagenesis and enhances genomic instability in Atm-deficient mice. Proc Natl Acad Sci USA. 2013;110:19920-5.

10. Parsons MJ, McCormick L, Janke L, Howard A, Bouchier-Hayes L, Green DR. Genetic deletion of caspase-2 accelerates MMTV/cneu-driven mammary carcinogenesis in mice. Cell Death Differ. 2013;20:1174-82.

11. Dorstyn L, Puccini J, Wilson CH, Shalini S, Nicola M, Moore S, et al. Caspase-2 deficiency promotes aberrant DNA-damage response and genetic instability. Cell Death Differ. 2012;19:1288-98.

12. Dawar S, Lim Y, Puccini J, White M, Thomas P, Bouchier-Hayes $\mathrm{L}$, et al. Caspase-2-mediated cell death is required for deleting aneuploid cells. Oncogene. 2017;36:2704-14.

13. Dawar S, Shahrin NH, Sladojevic N, D'Andrea RJ, Dorstyn L, Hiwase DK, et al. Impaired haematopoietic stem cell differentiation and enhanced skewing towards myeloid progenitors in aged caspase-2-deficient mice. Cell Death Dis. 2016;7:e2509.

14. Lim Y, De Bellis D, Dorstyn L, Kumar S. p53 accumulation following cytokinesis failure in the absence of caspase-2. Cell Death Differ. 2018;25:2050-2.

15. Fava LL, Schuler F, Sladky V, Haschka MD, Soratroi C, Eiterer $\mathrm{L}$, et al. The PIDDosome activates p53 in response to supernumerary centrosomes. Genes Dev. 2017;31:34-45.

16. Andersen JL, Johnson CE, Freel CD, Parrish AB, Day JL, Buchakjian MR, et al. Restraint of apoptosis during mitosis through interdomain phosphorylation of caspase-2. EMBO J. 2009;28:3216-27.

17. Shin S, Lee Y, Kim W, Ko H, Choi H, Kim K. Caspase-2 primes cancer cells for TRAIL-mediated apoptosis by processing procaspase-8. EMBO J. 2005;24:3532-42.

18. Nutt LK, Margolis SS, Jensen M, Herman CE, Dunphy WG, Rathmell JC, et al. Metabolic regulation of oocyte cell death through the CaMKII-mediated phosphorylation of caspase-2. Cell. 2005;123:89-103.

19. Pham DD, Bruelle C, Thi Do H, Pajanoja C, Jin C, Srinivasan V, et al. Caspase-2 and p75 neurotrophin receptor (p75NTR) are involved in the regulation of SREBP and lipid genes in hepatocyte cells. Cell Death Dis. 2019;10:537.

20. Chou YS, Yen CC, Chen WM, Lin YC, Wen YS, Ke WT, et al. Cytotoxic mechanism of PLK1 inhibitor GSK461364 against osteosarcoma: mitotic arrest, apoptosis, cellular senescence, and synergistic effect with paclitaxel. Int J Oncol. 2016;48:1187-94.

21. St-Denis NA, Derksen DR, Litchfield DW. Evidence for regulation of mitotic progression through temporal phosphorylation and dephosphorylation of CK2alpha. Mol Cell Biol. 2009;29:2068-81.

22. Brito DA, Rieder CL. The ability to survive mitosis in the presence of microtubule poisons differs significantly between human nontransformed (RPE-1) and cancer (U2OS, HeLa) cells. Cell Motil Cytoskelet. 2009;66:437-47.

23. Shi J, Orth JD, Mitchison T. Cell type variation in responses to antimitotic drugs that target microtubules and kinesin-5. Cancer Res. 2008;68:3269-76. 
24. Gnad F, Gunawardena J, Mann M. PHOSIDA 2011: the posttranslational modification database. Nucleic Acids Res. 2011;39: D253-260.

25. Parrish AB, Freel CD, Kornbluth S. Cellular mechanisms controlling caspase activation and function. Cold Spring Harb Perspect Biol. 2013;5:a008672.

26. Kumar S. Caspase 2 in apoptosis, the DNA damage response and tumour suppression: enigma no more? Nat Rev Cancer. 2009;9:897-903.

27. Baliga BC, Read SH, Kumar S. The biochemical mechanism of caspase-2 activation. Cell Death Differ. 2004;11:1234-41.

28. Read SH, Baliga BC, Ekert PG, Vaux DL, Kumar S. A novel Apaf-1-independent putative caspase-2 activation complex. J Cell Biol. 2002;159:739-45.

29. Butt AJ, Harvey NL, Parasivam G, Kumar S. Dimerization and autoprocessing of the Nedd2 (caspase-2) precursor requires both the prodomain and the carboxyl-terminal regions. J Biol Chem. 1998;273:6763-8.

30. Oliver TG, Meylan E, Chang GP, Xue W, Burke JR, Humpton TJ, et al. Caspase-2-mediated cleavage of Mdm2 creates a p53induced positive feedback loop. Mol Cell. 2011;43:57-71.

31. Talanian RV, Quinlan C, Trautz S, Hackett MC, Mankovich JA, Banach D, et al. Substrate specificities of caspase family proteases. J Biol Chem. 1997;272:9677-82.

32. Benkova B, Lozanov V, Ivanov IP, Mitev V. Evaluation of recombinant caspase specificity by competitive substrates. Anal Biochem. 2009;394:68-74.

33. Bouchier-Hayes L, Oberst A, McStay GP, Connell S, Tait SW, Dillon CP, et al. Characterization of cytoplasmic caspase-2 activation by induced proximity. Mol Cell. 2009;35:830-40.

34. Guse A, Mishima M, Glotzer M. Phosphorylation of ZEN-4/ MKLP1 by aurora B regulates completion of cytokinesis. Curr Biol. 2005;15:778-86.

35. Meraldi P, Honda R, Nigg EA. Aurora kinases link chromosome segregation and cell division to cancer susceptibility. Curr Opin Genet Dev. 2004;14:29-36.

36. Marugan C, Torres R, Lallena MJ. Phenotypic screening approaches to develop aurora kinase inhibitors: drug discovery perspectives. Front Oncol. 2015;5:299.

37. Straight AF, Cheung A, Limouze J, Chen I, Westwood NJ, Sellers JR, et al. Dissecting temporal and spatial control of cytokinesis with a myosin II Inhibitor. Science. 2003;299:1743-7.

38. Wong C, Stearns T. Mammalian cells lack checkpoints for tetraploidy, aberrant centrosome number, and cytokinesis failure. BMC Cell Biol. 2005;6:6.

39. Li H, Bergeron L, Cryns V, Pasternack MS, Zhu H, Shi L, et al. Activation of caspase-2 in apoptosis. $\mathrm{J}$ Biol Chem. 1997;272:21010-7.

40. Thornberry NA, Rano TA, Peterson EP, Rasper DM, Timkey T, Garcia-Calvo M, et al. A combinatorial approach defines specificities of members of the caspase family and granzyme B. Functional relationships established for key mediators of apoptosis. J Biol Chem. 1997;272:17907-11.
41. Tang Y, Wells JA, Arkin MR. Structural and enzymatic insights into caspase-2 protein substrate recognition and catalysis. J Biol Chem. 2011;286:34147-54.

42. Zamaraev AV, Kopeina GS, Prokhorova EA, Zhivotovsky B, Lavrik IN. Post-translational modification of caspases: the other side of apoptosis regulation. Trends Cell Biol. 2017;27:322-39.

43. Goldenson B, Crispino JD. The aurora kinases in cell cycle and leukemia. Oncogene. 2015;34:537-45.

44. D’Avino PP, Giansanti MG, Petronczki M. Cytokinesis in animal cells. Cold Spring Harb Perspect Biol. 2015;7:a015834.

45. D'Avino PP, Capalbo L. Regulation of midbody formation and function by mitotic kinases. Semin Cell Dev Biol. 2016;53:57-63.

46. Nutt LK, Buchakjian MR, Gan E, Darbandi R, Yoon SY, Wu JQ, et al. Metabolic control of oocyte apoptosis mediated by 14-33zeta-regulated dephosphorylation of caspase-2. Dev Cell. 2009;16:856-66.

47. Chieffi P. Aurora B: a new promising therapeutic target in cancer. Intractable Rare Dis Res. 2018;7:141-4.

48. O'Reilly LA, Ekert P, Harvey N, Marsden V, Cullen L, Vaux DL, et al. Caspase-2 is not required for thymocyte or neuronal apoptosis even though cleavage of caspase- 2 is dependent on both Apaf-1 and caspase-9. Cell Death Differ. 2002;9:832-41.

49. Colussi PA, Harvey NL, Kumar S. Prodomain-dependent nuclear localization of the caspase-2 (Nedd2) precursor. A novel function for a caspase prodomain. J Biol Chem. 1998;273:24535-42.

50. Wisniewski JR, Zougman A, Nagaraj N, Mann M. Universal sample preparation method for proteome analysis. Nat Methods. 2009;6:359-62.

51. Cox J, Neuhauser N, Michalski A, Scheltema RA, Olsen JV, Mann M. Andromeda: a peptide search engine integrated into the MaxQuant environment. J Proteome Res. 2011;10:1794-805.

52. Cox J, Mann M. MaxQuant enables high peptide identification rates, individualized p.p.b.-range mass accuracies and proteomewide protein quantification. Nat Biotechnol. 2008;26:1367-72.

53. Parsons MJ, Bouchier-Hayes L. Measuring initiator caspase activation by bimolecular fluorescence complementation. Cold Spring Harb Protoc. 2015;2015:pdb prot082552.

54. Dorstyn L, Kumar S. Caspase-2 protocols. Methods Mol Biol. 2014;1133:71-87.

55. Ran FA, Hsu PD, Wright J, Agarwala V, Scott DA, Zhang F. Genome engineering using the CRISPR-Cas9 system. Nat Protoc. 2013;8:2281-308

56. Zhu X, Xu Y, Yu S, Lu L, Ding M, Cheng J, et al. An efficient genotyping method for genome-modified animals and human cells generated with CRISPR/Cas9 system. Sci Rep. 2014;4:6420.

57. McKenzie C, Bassi ZI, Debski J, Gottardo M, Callaini G, Dadlez $\mathrm{M}$, et al. Cross-regulation between Aurora B and citron kinase controls midbody architecture in cytokinesis. Open Biol. 2016;6:160019.

58. Perez-Riverol Y, Csordas A, Bai J, Bernal-Llinares M, Hewapathirana S, Kundu DJ, et al. The PRIDE database and related tools and resources in 2019: improving support for quantification data. Nucleic Acids Res. 2019;47:D442-D450. 